\title{
Development and biochemical and immunological characterization of early passage and immortalized bovine intestinal epithelial cell lines from the ileum of a young calf
}

\author{
Pratik Katwal • Milton Thomas • Tirth Uprety • Michael B. Hildreth • \\ Radhey S. Kaushik
}

Received: 23 June 2018/Accepted: 21 October 2018/Published online: 1 January 2019

(C) Springer Nature B.V. 2019

\begin{abstract}
The intestinal epithelium is a major site of interaction with pathogens. In bovine intestinal epithelial cells (BIECs), Toll-like receptors (TLRs) play an important role in innate immune responses against enteric pathogens. This study is aimed at establishing a stable bovine intestinal epithelial cell line that can be maintained by a continuous passage so that studies on innate immune responses against various enteric pathogens can be performed. The main goal was to establish pure cultures of primary and immortalized bovine intestinal epithelial cells from the ileum and then characterize them biochemically and immunologically. Mixed epithelial and fibroblast bovine ileal intestinal cultures were first established from a 2-day old calf. Limiting dilution method was used to obtain a clone of epithelial cells which was characterized using immunocytochemistry (ICC). The selected clone BIEC-c4 was cytokeratin positive and expressed low levels of vimentin, confirming the epithelial cell phenotype. Early passage BIEC-c4 cells were transfected with either simian virus 40 (SV40) large $\mathrm{T}$ antigen or human telomerase reverse transcriptase (hTERT), or human papillomavirus (HPV) type 16E6/E7 genes to establish three immortalized BIEC cell lines. The expression of SV40, hTERT and
\end{abstract}

P. Katwal · M. Thomas · T. Uprety

M. B. Hildreth · R. S. Kaushik $(\bowtie)$

Department of Biology and Microbiology, South Dakota

State University, Brookings, SD 57007, USA

e-mail: Radhey.Kaushik@sdstate.edu
HPV E6/E7 genes in immortalized BIECs was confirmed by a polymerase chain reaction (PCR). Immunocytochemistry and immunofluorescence assays also confirmed the expression of SV40, hTERT and HPV E6 proteins. The immortalized BIECs were cytokeratin positive and all except HPV-BIECs expressed low levels of vimentin. A growth kinetics study indicated that there were no significant differences in the doubling time of immortalized BIECs as compared to early passage BIEC-c4 cells. All four BIEC types expressed TLR 1-10 genes, with TLR 3 and 4 showing higher expression across all cell types. These newly established early passage and immortalized BIEC cell lines should serve as a good model for studying infectivity, pathogenesis and innate immune responses against enteric pathogens.

Keywords Ileum - Bovine intestinal epithelial cells . Immortalization · SV40 · hTERT · HPV E6/E7 · Tolllike-receptors

\section{Introduction}

The gastrointestinal tract is the main site of entry to the body for many pathogens. Intestinal epithelial cells interact with enteric pathogens and mediate mucosal immune responses (Kaushik et al. 2008; Maynard et al. 2012; Rusu et al. 2005). These cells express various pattern recognition receptors (PRRs) of which 
Toll-like receptors (TLRs) are the most widely studied (Janeway 1989; Rakoff-Nahoum et al. 2004; Takanashi et al. 2013). The TLRs recognize pathogenassociated molecular patterns (PAMPs) of microbes which results in subsequent cell signaling and innate immune responses (Janeway 1989; Janeway and Medzhitov 2002; Medzhitov and Janeway 1997). Intestinal epithelial cell surface also expresses various glycoconjugates that may serve as receptors or entry factors for many enteric pathogens (Mestecky 2005).

Intestinal epithelial cell cultures from various animals including mouse, rabbit, and pigs have been reported (Booth et al. 1995, 1999; Kaeffer 2002; Kaeffer et al. 1993; Rusu et al. 2005; Vidrich et al. 1988). However, very few studies have described the establishment and characterization of primary bovine intestinal cell cultures. Bovine intestinal epithelial cell cultures have been established from the duodenum, jejunum, ileum, and colon of adult cattle and fetal calves (Birkner et al. 2004; Kaushik et al. 2008; Loret et al. 2009; Rusu et al. 2005; Yang et al. 2015; Zhan et al. 2017). Recently, intestinal epithelial cell culture established from the jejunum of buffalo has been reported (Chaudhary et al. 2018).

Establishment of primary intestinal cell cultures is a big challenge due to the high rate of cell death that occurs during cell isolation (Kaeffer 2002; Rusu et al. 2005). Also, frequent contamination of epithelial cells with fibroblasts is another impediment in the generation of pure epithelial cell cultures (Freshney 1994; Rusu et al. 2005). It is important to establish a stable cell culture system so that cells can proliferate for many generations without entering early replicative senescence (Freshney 1994; Rusu et al. 2005). This facilitates consistent and long-term studies on the interaction of intestinal epithelial cells with various enteric pathogens.

Innate immune receptors play a major role in host defense mechanisms through the early recognition of pathogens before effective adaptive immune responses can be mounted. PRRs can be broadly divided into two types: non-cytosolic receptors (expressed either on the cell membrane or within endosomal compartments) and cytosolic receptors. A total of ten bovine TLRs have been identified which are designated as TLRs 1-10 (Fisher et al. 2011; Menzies and Ingham 2006; Werling et al. 2006). In general, TLR1, TLR2, TLR4, TLR5, and TLR6 are expressed on the cell surface, while TLRs 3, 7, 8, and 9 are expressed in the cell within endosomal compartments and are mostly involved in the recognition of nucleic acids (Akira et al. 2006; Werling and Jungi 2003; Werling et al. 2006). These receptors broadly recognize different classes of pathogens and are also important in the recognition of danger signals of tissue damage (Iwasaki and Medzhitov 2010; Miyake 2007). This leads to the initiation of proinflammatory signaling cascade through activation of transcription factor NF- $\kappa$ B (Mogensen 2009). The proinflammatory response involves the production of various cytokines, chiefly IL-1, IL-6, and IL-18 and is a major step in the clearance of pathogens (Peterson and Artis 2014).

Many enteric pathogens infect young calves. Bovine rotavirus (BRV), bovine coronavirus (BCV), and bovine viral diarrhea virus (BVDV) infect epithelial enterocytes and cause severe diarrhea in young calves (Cho and Yoon 2014). Equally important are various bacterial pathogens, namely enterotoxigenic Escherichia coli, Clostridium perfringens, Mycobacterium avium subspecies paratuberculosis (MAP), Salmonella enterica; and the protozoan parasite Cryptosporidium parvum (C. parvum) (Cho and Yoon 2014; Foster and Smith 2009; Khare et al. 2009; Mohler et al. 2009; Rings 2004). Bovine jejunal and ileal epithelial cell cultures derived from adult cattle and fetal calves are currently available as homologous cell lines for studying innate immune responses against these pathogens (Kaushik et al. 2008). The fetal bovine intestinal epithelial cell line has been studied for interaction with enteric pathogens (Takanashi et al. 2013). Surgically prepared jejunal loops from 1-day old calves have also been used for comparative study of the innate immune responses against BRV and BCV infection (Aich et al. 2007). Therefore, BIEC cell lines from young calves can provide important knowledge on the innate immune responses against enteric pathogens that chiefly infect young calves.

The established epithelial cultures from fetal calf and adult cattle may not be a suitable model to study enteric infections of young calves (Kaushik et al. 2008). At present, only limited studies on intestinal epithelial cell cultures from young calves are available (Cencič and Langerholc 2010; Cencic et al. 2007; Steube et al. 2012). In this study, the main aim was to establish primary and immortalized cultures of bovine intestinal epithelial cells (BIECs) derived from young calf and then characterize them using biochemical and 
immunological techniques. A pure BIEC clone (BIEC-c4) was established and immortalized using SV40, hTERT, and HPV E6/E7 genes for establishing continuous cell lines. Growth kinetics of BIEC-c4 was compared with the immortalized BIECs. The expression of TLR genes was also studied in each of the four BIEC cell types. The BIEC cell lines established in this study may be applicable for understanding the role of intestinal epithelial cells in innate immunity against enteric pathogens. Therefore, these cells may be a useful model for studying epithelial cell biology, hostmicrobe interaction, immunomodulation, and pathogenesis.

\section{Materials and methods}

Establishment of primary and early passage bovine intestinal epithelial cultures

A 2-day-old colostrum-deprived Holstein male calf (Bos taurus) was obtained from the South Dakota State University (SDSU) dairy farm. The animal was negative for bovine viral diarrhea, bovine leukemia virus, and Johne's disease. All animal protocols were approved by SDSU Institutional Animal Care and Use Committee (IACUC). The ileal intestinal cultures were established using the procedures described earlier with some modification (Kaushik et al. 2008; Rusu et al. 2005). Briefly, ileal tissue fragments from a 2-day old dairy calf were collected in ice-cold Hanks balanced salt solution (HBSS) supplemented with $1 \%$ strepto-penicillin-antimycotic solution, gentamycin $(5 \mu \mathrm{g} / \mathrm{ml})$ and L-glutamine $(2 \mathrm{mM})$, referred as supplemented HBSS (HBSS-S). Intestinal lumen was flushed with HBSS-S and then both ends of the intestinal segment were ligated with silk suture. Intestinal loops were filled with phosphate-bufferedsaline (PBS) containing $1 \mathrm{mM}$ dithiothreitol and kept for 5-10 min in shaking water bath $\left(37^{\circ} \mathrm{C}\right)$ to remove the mucus. Subsequently, intestinal loops were filled with pre-warmed $\left(37^{\circ} \mathrm{C}\right) \mathrm{HBSS}-\mathrm{S}$ containing collagenase (300 units $/ \mathrm{ml}$ ) and dispase (0.24 units $/ \mathrm{ml})$ enzymes to digest the intestinal tissue. Collagenasedispase filled intestinal loops were kept in shaking water bath $\left(37^{\circ} \mathrm{C}\right)$ for $15 \mathrm{~min}$. Collagenase, type 2 and dispase-II were bought from Worthington Biochemical Corporation, NJ, USA (Cat \# LS004176) and Roche Diagnostics, IN, USA (Cat \# 50-100-3345) respectively. The contents obtained through this step were discarded. Then using the same collagenasedispase digestion medium, the digestion step was repeated for $45 \mathrm{~min}$ and the contents were discarded. Then ileal loops were opened longitudinally, and predigested epithelium was scraped using a sterile scalpel blade. The resulting contents were incubated with HBSS containing 2.4 units $/ \mathrm{ml}$ dispase for $10 \mathrm{~min}$. Cells obtained after enzymatic digestion of scraped tissue were washed and resuspended in Dulbecco's Modified Eagle's Medium (DMEM). The cell suspension was treated with DMEM containing 2\% sorbitol (Sigma) and centrifuged to remove the fibroblasts (Rusu et al. 2005). The pellet of cells was resuspended in DMEM medium containing $10 \%$ fetal calf serum (FCS; Atlanta Biologicals, GA, USA). Cells were then incubated at $37{ }^{\circ} \mathrm{C}$ for $90 \mathrm{~min}$ in a cell culture Primaria flask (Becton-Dickinson, Franklin Lakes, NJ) to remove adherent fibroblast-like cells. The nonadherent cells were collected, then centrifuged for $5 \mathrm{~min}$ at $195 \mathrm{~g}$ and resuspended in DMEM-2 medium. The DMEM-2 medium was composed of DMEM high glucose medium as base, HEPES buffer $(10 \mathrm{mM})$, antibiotic-antimycotic solution (1\%), gentamycin $(50 \mu \mathrm{g} / \mathrm{ml})$, L-glutamine $(2 \mathrm{mM})$, hydrocortisone (100 mM), apo-transferrin $(5 \mu \mathrm{g} / \mathrm{ml})$, epidermal growth factor $(25 \mathrm{ng} / \mathrm{ml})$, bovine insulin $(10 \mu \mathrm{g} / \mathrm{ml})$, Triiodothyronine $(20 \mathrm{ng} / \mathrm{ml})$, acid linoleic/albumin $(10 \mu \mathrm{g} / \mathrm{ml}), 1 \%$ non-essential amino acids and $2 \%$ FCS. The cell suspension was transferred to Primaria flasks and incubated at $37^{\circ} \mathrm{C}$ for the growth of ileal cells in primary cultures. Sub-cultivation of a primary culture begins, by convention, a cell line (Schaeffer 1990). For a cell line, the first dozen or so subcultivations results in cultures that can be referred to as an early passage cell line. An early passage cell line can be subjected to immortalization treatments to lead to an immortal cell line.

Instead of using DMEM-2 medium, a mixed culture of bovine ileal epithelial and fibroblast-like cells at passage 4 was cultured at $37{ }^{\circ} \mathrm{C}$ and $5 \% \mathrm{CO}_{2}$ in DMEM/F12 medium which is supplemented with $5 \%$ fetal bovine serum (FBS), $1 \%$ streptomycin-penicillin, $1 \%$ L-glutamine, $0.1 \%$ mouse epidermal growth factor (EGF) (Corning ${ }^{\circledR}$, Cat. No. 4069007), and 0.1\% each of insulin, human transferrin and selenous acid (ITS) (Corning $^{\circledR}$, Cat. No. 354351). This medium was designated as supplemented DMEM/F12 medium and had been previously used in our lab for the growth 
of porcine intestinal epithelial cells (Johnson et al. 2010; Koh et al. 2008). Cells were cultured in supplemented DMEM/F12 medium for the next 4 passages (up to 8 passages) where they showed a larger percentage of epithelial-like cells.

Further, a limiting dilution method was used to obtain pure bovine intestinal epithelial cell (BIEC) cultures from a mixed fibroblast and epithelial cell culture (Miyazawa et al. 2010). Briefly, the cells from passage 8 epithelial cell-enriched cultures were treated with $0.05 \%$ trypsin-EDTA for $5 \mathrm{~min}$ at $37^{\circ} \mathrm{C}$ to detach fibroblasts. These cells were discarded and remaining cells were again trypsinized to obtain epithelial-like cells. The epithelial-like cells were transferred to a petri dish $(100 \mathrm{~mm} \times 15 \mathrm{~mm})$ at a low density of 1000 cells (passage 9 ) in supplemented DMEM/F12 medium. After $48 \mathrm{~h}$, the selected clones were identified based on epithelial morphology and marked on the petri dish with a black marker. The growth of these clones was followed. After 4 days of incubation on the petri dish, cells were obtained from five selected clones. Sterilized small hollow plastic wells coated with vaseline at the bottom were used for separating the clones on the petri dish. Selected five clones were obtained by trypsinization and transferred to individual wells on a 24-well plate (passage 10) and further propagated. After $96 \mathrm{~h}$, cells from well number 4 were trypsinized and further propagated in 6-well plate (passage 11). These cells were further subcloned in a 96-well plate by serial dilution method (Miyazawa et al. 2010). A clone growing very well in the 96-well plate was further amplified in a 24 -well plate, then 6-well plate, and finally in a T-25 flask. These cells were kept for further studies and named as bovine intestinal epithelial cells obtained from colony 4 (BIEC-c4). The BIEC-c4 cells were then transferred and maintained in the T-75 flask by passaging using the same culture conditions and supplemented DMEM/F12 medium. Phase contrast photographs of cells at various stages of the establishment of epithelial cultures were taken at $10 \times$ or $20 \times$ magnification using an Olympus IX70 inverted microscope.

Immunocytochemical staining of early passage and immortalized BIEC-c4 cells for cell markers

Immunocytochemical (ICC) staining of primary and immortalized BIEC cells was performed using earlier described protocols (Kaushik et al. 2008; Thomas et al. 2018). Briefly, primary and immortalized BIECc4 cells were cultured in a T-75 flask in the supplemented DMEM/F12 medium. After $48 \mathrm{~h}$, cells were trypsinized and a cell suspension at a concentration of $1 \times 10^{6}$ cells $/ \mathrm{ml}$ was prepared in DMEM/F12 medium. Then, $100 \mu \mathrm{l}$ of the suspension was used to prepare each cytospin using a cytofuge (Cytospin 3; Thermo Shandon Inc., Cheshire, UK) at $800 \mathrm{rpm}$ for $5 \mathrm{~min}$. The cytospins were air dried for $1 \mathrm{~h}$ and fixed with absolute acetone for $7 \mathrm{~min}$. The slides were washed three times with $1 \times$ phosphate-buffered saline (PBS) for $5 \mathrm{~min}$ and incubated at room temperature with $1 \times$ PBS containing $0.1 \%$ sodium azide and $0.3 \%$ hydrogen peroxide $\left(\mathrm{H}_{2} \mathrm{O}_{2}\right)$ to block endogenous peroxidase activity. The cells were blocked for non-specific protein binding using $1 \%$ goat serum in PBS. Each slide was washed once with $1 \times$ PBS and then incubated in a humid chamber for $1 \mathrm{~h}$ with $100 \mu \mathrm{l}$ of primary antibodies diluted at a final concentration of $1 \mu \mathrm{g} / \mathrm{ml}$. The presence of cytokeratin, vimentin, alpha-smooth muscle actin, and desmin proteins was detected by ICC staining using anticytokeratin monoclonal antibody (mAb) C6909 (clone $\mathrm{K} 8.13$, IgG2a isotype), anti-vimentin mAb V5255 (IgM isotype), anti-alpha smooth muscle actin mAb A2547 (IgG2a) and anti-desmin mAb D1033 (IgG1) respectively (Kaushik et al. 2008; Sun et al. 2012; Thomas et al. 2018). As isotype-matched controls, mAbs M9269 (IgG1 isotype), M9144 (IgG2a isotype) and M5170 (IgM isotype) were used. All of these primary antibodies were purchased from SigmaAldrich, St. Louis, MO, USA. The mAb C6909 was specific for polypeptides of cytokeratins $1,5,6,7,8$, 10,11 , and 18. As a negative control, cells were incubated with PBS containing $1 \%$ goat serum. Further, all slides were washed three times with $1 \times$ PBS, followed by incubation for $30 \mathrm{~min}$ with $100 \mu \mathrm{l}$ of isotype-specific, biotinylated goat anti-mouse IgG1 (Caltag Laboratories, M32115), IgG2a (Caltag Laboratories, M32215) or IgM (Caltag Laboratories, M31515) secondary antibody at 1:2000 dilution. The cytospins were washed three times with $1 \times$ PBS and treated with ready-to-use (RTU) HRP-streptavidin solution from Vector Elite vectastain kit (Vector Laboratories, Burlingame, CA, USA) for $30 \mathrm{~min}$. After three washes with $1 \times$ PBS, each slide was incubated for 10 min with $100 \mu$ of RTU diaminobenzene (DAB) substrate (Vector Laboratories, Burlingame, CA, USA) and counterstained for 2 min with 
hematoxylin (Vector Laboratories, Burlingame, CA, USA). Slides were then washed in running tap water, air dried overnight, and mounted with a coverslip and cytoseal 60 mounting medium (Thermo Scientific, Waltham, MA, USA). Images were taken at $20 \times$ magnification using an Olympus AX70 microscope.

\section{Polarization of BIEC-c4 cells}

The polarization of primary BIEC-c4 cells was performed using the methods described earlier (Johnson et al. 2010). To each of the three wells in a 6-well plate, $2 \mathrm{ml}$ of DMEM/F12 media was added. Then transwell-inserts $\left(0.4 \mu \mathrm{m}\right.$ pore size, $4 \times 10^{6}$ pores/ $\mathrm{cm}^{2}$, polyester membrane) $\left(\right.$ Costar $^{\circledR}$ Transwell $\left.^{\circledR}\right)$ were placed over each of the three wells. Briefly, $5 \times 10^{5}$ cells of BIEC-c4 (passage \# 24) in $2 \mathrm{ml} \mathrm{DMEM/F12}$ medium were transferred to a transwell insert in the first well. The insert in the second well contained media alone without cells (negative control) while the positive control in third well had insert seeded with the porcine jejunal epithelial cell (IPEC-J2, passage \# 57) (Geens and Niewold 2011; Johnson et al. 2010). The 6-well plate was incubated at $37{ }^{\circ} \mathrm{C}$ and $5 \% \mathrm{CO}_{2}$. Every $24 \mathrm{~h}$, transepithelial electrical resistance (TEER) was measured using a standard procedure (Miyazawa et al. 2010). The electrode was connected to EVOM voltmeter (World Precision Instruments) and then set to measure resistance in ohm $(\Omega)$. Every $48 \mathrm{~h}$, media in both the wells containing cells was replaced without disturbing the cells. TEER measurements were taken for all three wells for a period of 7 days.

Generation of SV40, hTERT and HPV E6/E7 immortalized BIECs

Approximately $5 \times 10^{5}$ cells of the BIEC-c4 clone were seeded into a 6-well tissue culture plate. After $18 \mathrm{~h}$ incubation at $37{ }^{\circ} \mathrm{C}$, cells in two wells were washed with sterile $1 \times$ PBS and transfected with either the pSV3-neo $\left(\right.$ ATCC $^{\circledR}$ 37150) plasmid vector with SV40 gene or the pGRN145 plasmid vector with hTERT gene (ATCC ${ }^{\circledR}$ MBA-141) using Lipofectamine ${ }^{\circledR} 2000$ reagent according to the manufacturer's protocol. Cells were then incubated with serum-free OPTI-MEM $^{\circledR}$ media for $6 \mathrm{~h}$ at $37{ }^{\circ} \mathrm{C}$ after which selection antibiotics were added to assess successful transfection and immortalization of cells. Transfected cells were selected using either G418 antibiotic (Thermo Fisher, Waltham, MA, USA, Cat. No. $10131-035 ; 1000 \mu \mathrm{g} / \mathrm{ml}$ concentration) for 7 days (SV40 immortalization, plate 1) or Hygromycin B (EMD Millipore, Burlington, MA, USA, Cat. No. $400052 ; 100 \mu \mathrm{g} / \mathrm{ml}$ concentration) for 14 days (hTERT immortalization, plate 2). The BIEC-c4 cells in one well were grown in the absence of selection antibiotics (positive control for cell growth). The untransfected BIEC-c4 cells in remaining well were treated with selection antibiotics to observe cell death. Selected colonies generated from transfected cells were propagated separately and culture stocks for each of SV40-BIEC and hTERT-BIEC were prepared. The BIEC-c4 cells at passages 33 and 27 were used for transfection with SV40 and hTERT genes respectively. PA317 LXSN 16E6E7 cells (ATCC ${ }^{\circledR}$ CRL2203) were cultured in DMEM-10 medium and the supernatant was collected after 5-7 days growth of these cells. Pooled supernatant derived from culturing PA317 LXSN 16E6E7 cells was used for inducing HPV E6/E7 immortalization of BIEC-c4 cells. Approximately, $0.3 \times 10^{6}$ cells of BIEC-c4 at passage 37 were seeded on a 6 -well plate. After $48 \mathrm{~h}$, BIEC-c4 cells maintained in OPTI-MEM ${ }^{\circledR}$ serum-free media were transfected with the supernatant obtained from PA317 LXSN 16E6E7 using Lipofectamine ${ }^{\circledR}$ 2000 reagent. Similar to the above-described protocol, transfected cells were selected by treating with G418 antibiotic at $1000 \mu \mathrm{g} / \mathrm{ml}$ for 15 days. The cells were further propagated in a T-75 flask and stocks were prepared.

Polymerase chain reaction (PCR) for detection of genes used to immortalize BIEC-c4 cells

DNA was isolated from each of the three immortalized BIECs: SV40-BIEC, hTERT-BIEC and HPV-BIEC cells using a DNeasy Blood \& Tissue Kit (Qiagen, Valencia, CA, USA), and the concentration of DNA obtained from each BIEC type was measured using a Nanodrop ND-1000 Spectrophotometer. To confirm the presence of SV40, hTERT, and HPV E6/E7 genes in the immortalized BIECs, PCR was conducted using primers specific to these genes (Table 1). All the PCR reactions were performed using Taq PCR Kit (New England Biolabs, Ipswich, MA, USA) and the following amplification conditions were used: initial denaturation at $95{ }^{\circ} \mathrm{C}$ for $10 \mathrm{~min}$, followed by 50 cycles of: 
Table 1 Summary of genes used to immortalize BIEC-c4 cells and PCR conditions

\begin{tabular}{|c|c|c|c|c|}
\hline Gene & Primer sequences: forward $(F)$ and reverse $(R)$ & Ann. temp. ${ }^{\mathrm{a}}$ & Product size ${ }^{\mathrm{b}}$ & Source \\
\hline SV40 & $\begin{array}{l}\text { F: GCATGACTCAAAAAACTTAGCAATTCTG } \\
\text { R: TGAGGCTACTGCTGACTCTCAACA }\end{array}$ & 60 & 105 & Jin et al. (2004) \\
\hline hTERT & $\begin{array}{l}\text { F: GGCTGAAGTGTCACAGCCTG } \\
\text { R: GTGGATCCGCACGTGAGAAT }\end{array}$ & 60 & 525 & Bodnar et al. (1998) \\
\hline HPV-E6E7 & $\begin{array}{l}\text { F: ATGCATAGTATATAGAGATGGGAAT } \\
\text { R: CTGCAGGATCAGCCATGGTAGA }\end{array}$ & 55 & 628 & Chen et al. (2006) \\
\hline
\end{tabular}

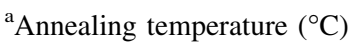

${ }^{\mathrm{b}} \mathrm{PCR}$ product size in base pairs $(\mathrm{bp})$

(1) denaturation at $94{ }^{\circ} \mathrm{C}$ for $30 \mathrm{~s},(2)$ annealing at $60{ }^{\circ} \mathrm{C}$ (SV40 and hTERT genes) or $55^{\circ} \mathrm{C}$ (HPV E6/E7 gene) for $30 \mathrm{~s}$, (3) extension at $72{ }^{\circ} \mathrm{C}$ for $1 \mathrm{~min}$; and final extension at $72{ }^{\circ} \mathrm{C}$ for $7 \mathrm{~min}$. The PCR products were resolved on a $1.5 \%$ agarose gel at $80 \mathrm{~V}$ for 25 min. The pLXSN-16E6E7 plasmid was kindly provided by Dr. Xiuqing Wang (Wang and Moutsoglou 2009).

Immunocytochemical staining of immortalized BIECs for the expression of specific proteins

The SV40-BIEC and hTERT-BIEC cells were cultured in two separate T-75 flasks in DMEM/F12 medium supplemented with 5\% FBS. After $48 \mathrm{~h}$ of incubation at $37{ }^{\circ} \mathrm{C}$, when cells were $80 \%$ confluent, they were trypsinized with $0.05 \%$ trypsin-EDTA. Then cytospins with $1 \times 10^{5}$ cells were prepared using a cytofuge (Cytospin 3; Thermo Shandon Inc., Cheshire, UK). Immunocytochemical (ICC) staining was performed for the confirmation of SV40 large T antigen (LT Ag) and hTERT proteins in SV40 and hTERT-BIEC cells respectively. For the detection of SV40 protein, ICC staining was performed using $100 \mu \mathrm{l}$ of mouse anti-SV40 specific monoclonal IgG2a antibody (Santa Cruz Biotechnology, Dallas, TX, USA; sc-53488) at 1:50 dilution. For the detection of TERT protein in hTERT immortalized BIECs, ICC staining was performed using $100 \mu \mathrm{l}$ of rabbit antihTERT (H-231) specific polyclonal IgG antibody (Santa Cruz Biotechnology, Dallas, TX, USA; sc7212) at 1:50 dilution. As isotype-matched controls, mAbs M9144 (mouse IgG2a isotype) and sc-3888 (rabbit $\mathrm{IgG}$ isotype) were used. The mouse $\operatorname{IgG} 2 \mathrm{a}$ isotype was purchased from Sigma (St. Louis, MO,
USA), and the rabbit IgG isotype was purchased from Santa Cruz Biotechnology (Dallas, TX, USA). Cells without primary antibody staining were used as negative control. After incubation in a humid chamber for $1 \mathrm{~h}$, cytospins were washed three times with $1 \times$ PBS and then incubated with $100 \mu \mathrm{l}$ of isotypespecific, biotinylated goat anti-mouse IgG2a (Caltag Laboratories, M32215) or Goat anti-rabbit IgG secondary antibody (Southern Biotech, Birmingham, AL, USA; 4050-08). After incubation at $37{ }^{\circ} \mathrm{C}$ for $30 \mathrm{~min}$, cells were washed in $1 \times$ PBS and stained with HRPstreptavidin for $30 \mathrm{~min}$ followed by DAB substrate (Vector Laboratories, Burlingame, CA, USA). Slides were then washed two times with $1 \times$ PBS and counterstained for $2 \mathrm{~min}$ with hematoxylin. After washing in running tap water, slides were air dried overnight, then mounted with a coverslip and cytoseal 60 mounting medium (Thermo Scientific, Waltham, MA, USA; 8310-4) and viewed under a $20 \times$ magnification using an Olympus AX70 microscope.

Indirect immunofluorescence assay

for the detection of HPVE6 protein

The BIEC-c4 and HPV-BIEC cells were cultured in two separate T-75 flasks in DMEM/F12 medium supplemented with $5 \%$ FBS. After $48 \mathrm{~h}$ of incubation at $37{ }^{\circ} \mathrm{C}$, cells were trypsinized with $0.05 \%$ trypsinEDTA and cytospins with $1 \times 10^{5}$ cells were prepared using a cytofuge (Cytospin 3; Thermo Shandon Inc.). The cytospins were air dried at room temperature for $90 \mathrm{~min}$, fixed in absolute acetone for $7 \mathrm{~min}$, dried, stored at $4{ }^{\circ} \mathrm{C}$ overnight, and blocked with $1 \%$ chicken serum for $15 \mathrm{~min}$. Immunofluorescence staining for HPV E6 protein was performed by incubating the 
HPV-BIECs cytospin for $90 \mathrm{~min}$ at room temperature with $150 \mu$ of goat anti-HPV16E6 specific polyclonal IgG antibody (Santa Cruz Biotechnology, Dallas, TX, USA; sc-1584) at 1:50 dil. The slide was then washed $3 \times$ with $1 \times$ PBS and incubated at room temperature for $1 \mathrm{~h}$ with $200 \mu \mathrm{l}$ of Alexa Fluor 488 conjugated chicken anti-goat IgG secondary antibody (Invitrogen, Grand Island, NY, USA; Cat. No. A-21467) at 1:200 dilution. Following incubation, the cytospin was washed with $1 \times$ PBS three times and then counterstained with $150 \mu \mathrm{l}$ of $1.5 \mathrm{mM}$ propidium iodide for $5 \mathrm{~min}$. Then it was washed once, air dried, and mounted with permafluor mounting reagent. Photographs were taken at a $20 \times$ magnification using an Olympus AX70 epifluorescence microscope (Olympus Corp., Tokyo, Japan).

\section{Cell growth kinetics study}

Approximately, 20,000 cells of BIEC-c4, SV40BIEC, hTERT-BIEC, and HPV-BIEC were seeded in 6-well plates. Five 6-well plates were cultured with all four BIEC cell types and incubated at $37{ }^{\circ} \mathrm{C}$. After $48 \mathrm{~h}$, the first plate was taken out; each well was trypsinized and counted using hemocytometer. The number of cells for each cell type was counted every $24 \mathrm{~h}$, beginning on day 2 and counted until day 6 . The same procedure was repeated two more times with all cell types. The time required by the culture to double in population, also called the doubling time (DT), was calculated by using the formula: DT $=\mathrm{T} \ln 2 / \ln (\mathrm{X} 2 /$ $\mathrm{X} 1$ ), where $\mathrm{T}$ is the incubation time in hours, $\mathrm{X} 1$ is the cell number at the beginning of the incubation time and X2 is the cell number at the end of the incubation time (Miyazawa et al. 2010).

\section{RNA extraction and cDNA preparation}

Early passage BIEC-c4 cells and the three immortalized BIECs (hTERT, SV40, and HPV E6/E7) were used for RNA isolation. Approximately $5 \times 10^{5}$ cells per well were cultured in two wells of a 6 -well plate. For each cell type, cells were cultured in a separate 6-well plate. After $18 \mathrm{~h}, 1 \times 10^{6}$ cells of each cell type were used for RNA extraction. Total RNA from bovine intestinal epithelial cells was extracted using a RNeasy Mini Kit (Qiagen, Valencia, CA, USA). RNA concentration in the four samples was determined using a Nanodrop ND-2000 Spectrophotometer. One $\mu \mathrm{g}$ of RNA was reverse transcribed using a TaqMan ${ }^{\circledR}$ Reverse Transcription Reagents Kit (Applied Biosystems, NJ, USA), following the manufacturer's protocol, to obtain $20 \mu \mathrm{l}$ of cDNA. Briefly, the protocol of cDNA synthesis involved preparing two mixtures: mixture I and mixture II. Mixture I contained 1ug of RNA and 1 ul of oligo dT 16, and mixture II contained $10 \times$ RT buffer, $25 \mathrm{mM} \mathrm{MgCl} 2,10 \mathrm{mM}$ dNTP mix, $0.1 \mathrm{mM}$ dTT, 1 ul of RNase inhibitor, and 1 ul of Multiscribe RT $(50 \mathrm{U} / \mu \mathrm{l})$. Mixture I was incubated at $65{ }^{\circ} \mathrm{C}$ for $5 \mathrm{~min}$ followed by incubation at $4{ }^{\circ} \mathrm{C}$ for $2 \mathrm{~min}$. It was then mixed with mixture II and final volume was made to $20 \mu \mathrm{l}$ by adding nuclease-free water. This new mixture was incubated at $37{ }^{\circ} \mathrm{C}$ for $30 \mathrm{~min}$, then at $95{ }^{\circ} \mathrm{C}$ for $5 \mathrm{~min}$ and $4{ }^{\circ} \mathrm{C}$ until final storage at $-20^{\circ} \mathrm{C}$. The cDNA was diluted fivefold in nuclease-free water to make working stock.

Quantitative analysis of TLR expression by realtime reverse transcription PCR

The quantification of TLR mRNA in bovine intestinal epithelial cell lines was accomplished using two-step real-time RT-PCR (QuantStudio ${ }^{\text {TM }} 6$ Flex Real-Time PCR System; Applied Biosystems, NJ, USA) using $\mathrm{RT}^{2} \mathrm{SYBR}^{\circledR}$ Green/ROX qPCR Mastermix (Qiagen, Valencia, CA, USA). TLR mRNA gene amplification was done using following PCR cycling conditions: $2 \mathrm{~min}$ at $50{ }^{\circ} \mathrm{C}$; $10 \mathrm{~min}$ at $95{ }^{\circ} \mathrm{C}$; followed by 40 cycles of $45 \mathrm{~s}$ at $95{ }^{\circ} \mathrm{C}, 30 \mathrm{~s}$ at $60{ }^{\circ} \mathrm{C}$ and $30 \mathrm{~s}$ at $72{ }^{\circ} \mathrm{C}$. The reaction mixture for each TLR contained $2 \mu \mathrm{l}$ of cDNA and $10 \mu \mathrm{l}$ of $2 \times$ mastermix with $1 \mu \mathrm{l}$ each of forward and reverse primer. A total reaction volume of $20 \mu \mathrm{l}$ was prepared by adding nuclease-free water. Altogether, ten sets of primers (Table 2) were used for amplification of bovine TLR 1-10 genes (Takanashi et al. 2013). The housekeeping gene hypoxanthine phosphoribosyltransferase-1 (HPRT-1) was used for normalization and comparing the expression levels of TLR genes. Gene amplification was calculated with the following formula: change in cycle threshold $(\Delta \mathrm{Ct})=\mathrm{Ct}$ of the gene of interest $-\mathrm{Ct}$ of HPRT-1. A lower $\Delta \mathrm{Ct}$ value represented a higher concentration of the gene of interest. 
Table 2 Primer sequences of bovine TLRs and the housekeeping gene

\begin{tabular}{|c|c|c|}
\hline Gene & Primer sequences: forward $(F)$ and reverse $(R)$ & Access. no. ${ }^{a}$ \\
\hline TLR1 & $\begin{array}{l}\text { F: CAT TCC TAG CAG CTA CCA CAA GCT } \\
\text { R: TGG GCC ATT CCA AAT AAG TTC T }\end{array}$ & NM_001046504 \\
\hline TLR2 & $\begin{array}{l}\text { F: GGG TGC TGT GTC ACC GTT TC } \\
\text { R: GCC ACG CCC ACA TCA TCT }\end{array}$ & NM_174197 \\
\hline TLR3 & $\begin{array}{l}\text { F: GGG CAC CTG GAG GTC CTT } \\
\text { R: TTC CTG GCC TGT GAG TTC TTG }\end{array}$ & NM_001008664 \\
\hline TLR4 & $\begin{array}{l}\text { F: AGC ACC TAT GAT GCC TTT GTC A } \\
\text { R: GTT CAT TCC GCA CCC AGT CT }\end{array}$ & NM_174198 \\
\hline TLR5 & $\begin{array}{l}\text { F: GTC CCC AAC ACC ACC AAG AG } \\
\text { R: GCG GTT GTG ACT GTC CTG ATA TAG }\end{array}$ & NM_001040501 \\
\hline TLR6 & $\begin{array}{l}\text { F: TTT ACC CTC AAC CAC GTG GAA } \\
\text { R: GGG CCA AAG GAA CTG AAA AAC }\end{array}$ & NM_001001159 \\
\hline TLR7 & $\begin{array}{l}\text { F: CAC CAA CCT TAC CCT CAC CAT T } \\
\text { R: GTC CAG CCG GTG AAA GGA }\end{array}$ & NM_001033761 \\
\hline TLR8 & $\begin{array}{l}\text { F: TGT GTT TAG AGG AAA GGG ATT GG } \\
\text { R: TCT GCA TGA GGT TGT CGA TGA }\end{array}$ & NM_001033937 \\
\hline TLR9 & $\begin{array}{l}\text { F: CAG TGG CCA GGG TAG TTT CTG } \\
\text { R: CCG GTT ATA GAA GTG ACG GTT GT }\end{array}$ & NM_183081 \\
\hline TLR10 & $\begin{array}{l}\text { F: TCT ACT GCA TCC CTA CCA GAT ATC C } \\
\text { R: GGG CCA TTC CAA GTA TGC TTT }\end{array}$ & NM_001076918 \\
\hline HPRT- $1^{b}$ & F: GGA TTA CAT CAA AGC ACT GAA CA & NM_001034035 \\
\hline
\end{tabular}

${ }^{\mathrm{a}}$ Gen Bank Accession

Number

${ }^{\mathrm{b}}$ Housekeeping gene

(Takanashi et al. 2013)
The cells in the first passage adhered to the flask, grew well in isolated clusters, and showed a mixed fibroblast and epithelial-like phenotype (Fig. 1a, b). Upon further passage to new flasks, cells continued to grow in clusters with an enriched epithelial-like phenotype, but fibroblast-like cells were still present in these cultures (Fig. 1c, d). As supplemented DMEM/F12 medium has been successfully used to culture porcine intestinal epithelial cells, we cultured the fibroblast and epithelial-like cultures from passage 4 onwards in supplemented DMEM/F12 medium instead of DMEM-2 medium. In passage 8 cultures, mixed fibroblast and epithelial-like cells were present in some locations (Fig. 2a) while at other places, distinct epithelial-like clusters were present (Fig. 2b). Thus, at passage 8 , we decided to culture these cells in a petri dish in low numbers (1000 cells per petri dish) in order to get individualized epithelial-like cell clusters (Fig. 2c, d). The individual epithelial like clusters were collected and amplified in 24 and 6-well plates. Then the cells from colony 4 from the petri dish were further subcloned in a 96-well plate and amplified further. These cells were designated as BIEC-c4 cells. Upon confluency, BIEC-c4 cells had a cobble-stone 
A

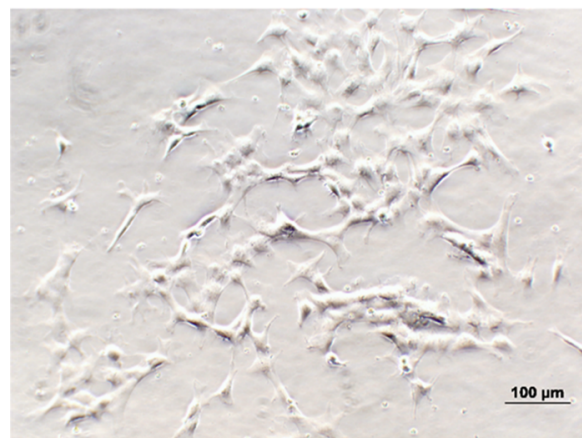

C

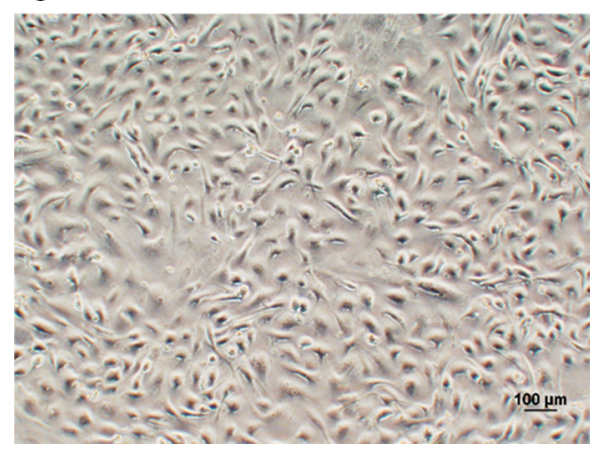

Fig. 1 Early passage bovine ileal cells cultured in DMEM-2 medium. Phase contrast pictures show mixed culture of epithelial and fibroblasts like cells based on morphological

morphology, indicative of epithelial phenotype (Fig. 3a). We expected that primary BIEC cells would have limited growth potential in subsequent passages so primary BIEC-c4 cells were further immortalized using SV40 gene (Fig. 3b), hTERT gene (Fig. 3c), and human papilloma virus HPV E6/E7 genes (Fig. 3d). All the three immortalized BIEC cell types also showed a cobble-stone morphology upon confluency (Fig. 3b, d).

The BIEC-c4 cells and three immortalized BIEC cell types were further characterized by immunocytochemistry using cell marker-specific antibodies. Mouse $\operatorname{IgG}, \operatorname{IgG} 2 \mathrm{a}$ and $\operatorname{IgM}$ antibodies were used as isotype controls for cytokeratin, vimentin, alpha smooth muscle actin, and desmin staining respectively. The anti-cytokeratin IgG2a antibody used for ICC was specific for cytokeratins $1,5,6,7,8,10,11$, and 18. Isotype control antibodies did not stain any of the cells (Fig. 4a, b). Primary BIEC-c4 cells and the BIECs immortalized with SV40, hTERT, and HPV E6/E7 genes expressed cytokeratin (Fig. 4c, e, g, i). Low levels of vimentin expression were detected in
B

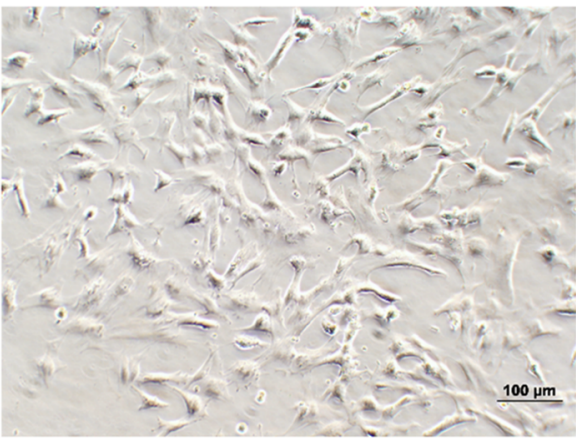

D

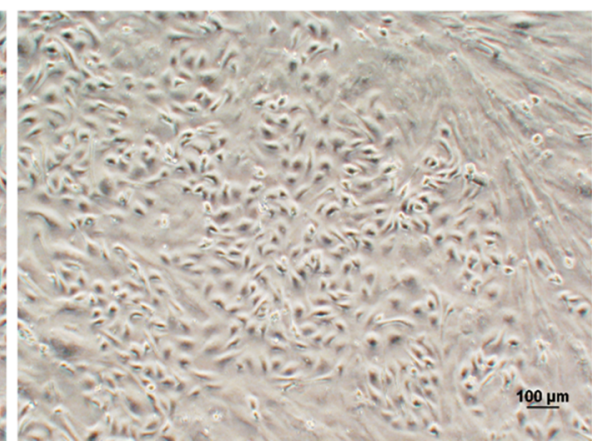

characteristics at passage $1(\mathbf{a}, \mathbf{b})$ and passage $3(\mathbf{c}, \mathbf{d})$. Pictures (a-d were taken at $10 \times$ magnification and bar indicate $100 \mu \mathrm{m}$ length

primary BIEC-c4 cells, SV40-BIECs, and hTERTBIECs (Fig. 4d, f, h). Vimentin expression was not detected in HPV-BIECs (Fig. 4j). Alpha-smooth muscle actin and desmin proteins were not expressed in both primary BIEC-c4 and immortalized SV40 and hTERT BIECs (data not shown).

Confirmation of immortalization of BIEC-c 4 cells by PCR and protein expression

The expression of hTERT, SV40, and HPV E6/E7 genes in the immortalized BIECs (Fig. 5a-c) were confirmed using the oligonucleotide primers specific to each gene using PCR (Table 1). The genomic DNA extracted from SV40-BIEC was used as a template to amplify SV40 gene which yielded a product of 105 base pairs when resolved on $1.5 \%$ agarose gel (Fig. 5b). Similarly, genomic DNA isolated from hTERT and HPV immortalized BIECs yielded amplified PCR products of 525 bp (Fig. 5a) and $628 \mathrm{bp}$ (Fig. 5c) length respectively. A DNA ladder of 100 base pairs was run to confirm the size of PCR products 
A

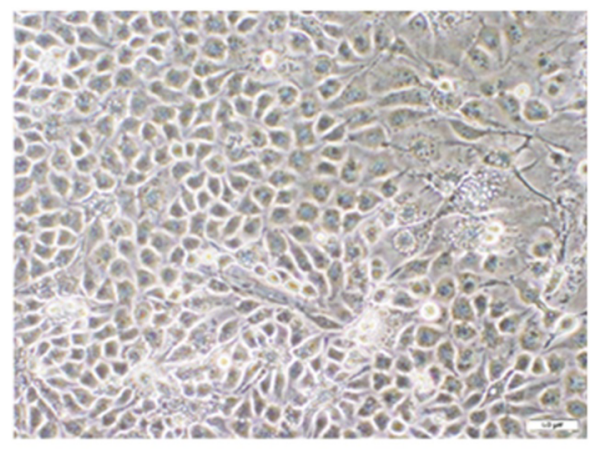

C

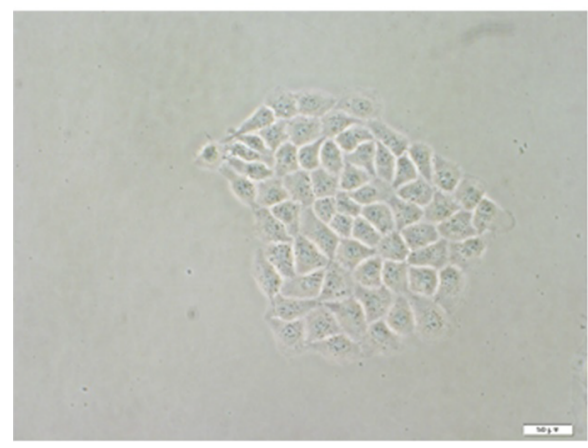

B

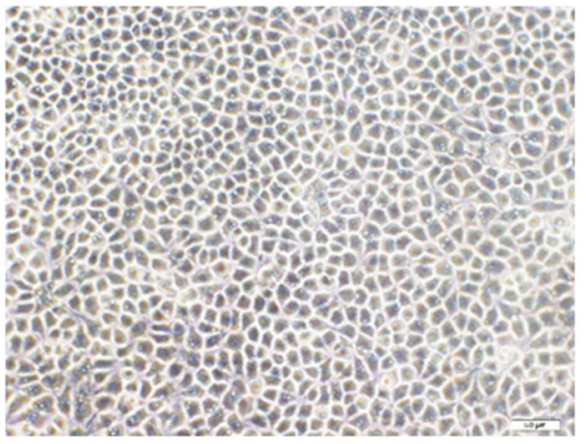

D

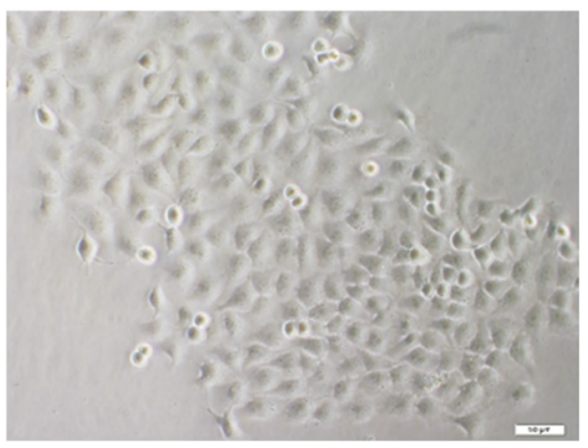

like cells (b) in the same flask at passage 8. Phase contrast pictures also show single cell-clusters present in the petri dish at passage $9(\mathbf{c}, \mathbf{d})$. Pictures were taken at $20 \times$ magnification and scale bar indicates $50 \mu \mathrm{m}$ length

488 conjugated secondary antibody (Fig. $7 \mathrm{~g}$ ), and propidium iodide staining for the nucleus (Fig. 7h). As a negative control, BIEC-c4 cells were also stained using a similar set of primary and secondary antibodies (Fig. 7d). However, primary BIEC-c4 cells did not express HPV E6 protein, as evident from the lack of immunofluorescence staining in the nucleus of BIECc4 cells (Fig. 7d, f). Some immunoreactivity was observed in the negative control BIEC-c4 cells (Fig. 7d). However, it was also non-specific cytoplasmic staining since the HPV protein in HPV-BIEC was specifically expressed in the nucleus (Fig. 7g, i). Also, BIEC-c4 cells with no primary antibody (treated with $1 \%$ chicken serum) did not show any staining for the HPV E6 protein, confirming the specificity of secondary antibody binding (Fig. 7a, c). 
$\mathbf{A}$

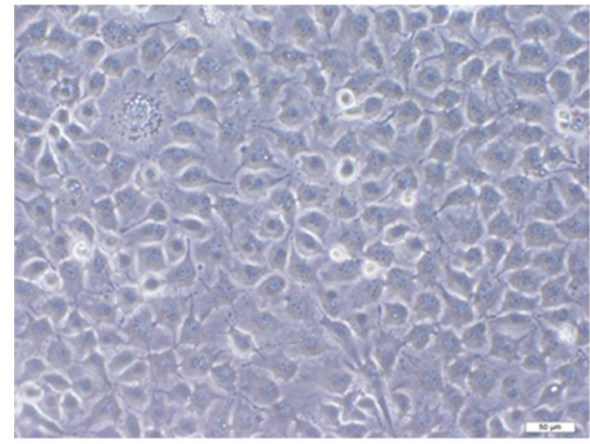

C

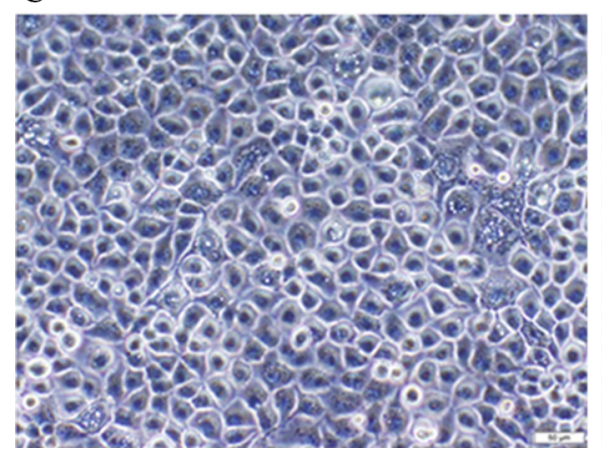

Fig. 3 Early passage bovine intestinal epithelial cells (BIECc4) and immortalized BIECs. a BIEC-c4 cells at passage 19. b SV40 immortalized BIECs at passage 36. c hTERT

Polarization and measurement of transepithelial electrical resistance

Analysis of the tight junction formation and polarization of BIEC-c4 cells was performed by measuring the transepithelial electrical resistance (TEER) for both BIEC-c4 cells and IPEC-J2 as positive control cells every $24 \mathrm{~h}$, over a period of 7 days. The resistance of BIEC-c4 cells did not increase with time and remained the same as the negative control well (filter without cells), varying between 101 and $124 \Omega$. In contrast, the measurement of resistance in IPEC-J2 cells increased every $24 \mathrm{~h}$ until day 5 , beginning at $154 \Omega$, and then reaching a maximum of $2830 \Omega$ on day 5 (data not shown).

Growth kinetics analysis of early passage and immortalized BIECs

Growth kinetics was studied for all four types of BIECs. Cells were counted every $24 \mathrm{~h}$, beginning on day 2 , until day 6 . Growth curves were plotted and
B

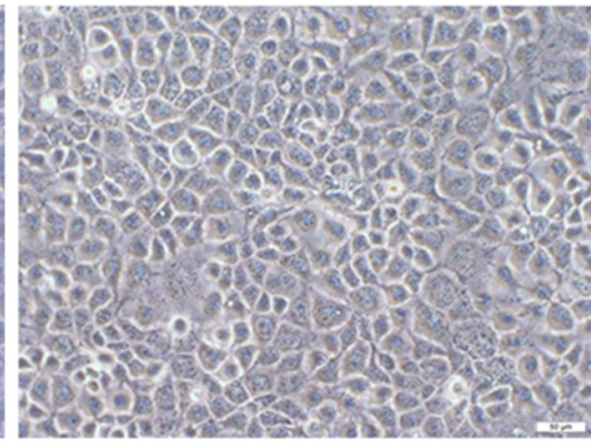

D

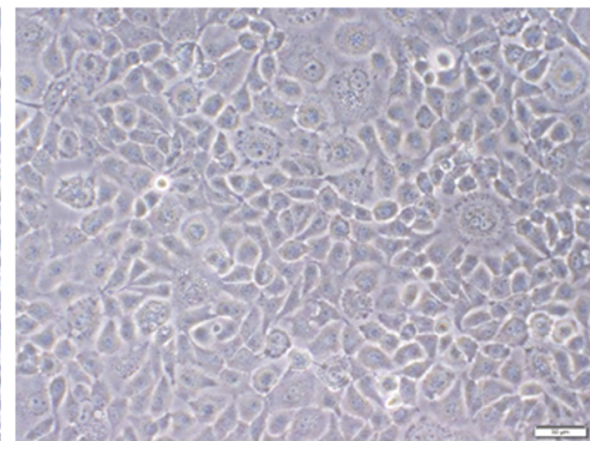

immortalized BIECs at passage 34. d HPV E6/E7 immortalized BIECs at passage 48 . Pictures were taken at $20 \times$ magnification and scale bar indicates $50 \mu \mathrm{m}$ length

mean doubling time was calculated for all four BIEC cell types (Fig. 8a). BIEC-c4, SV40-BIEC, hTERTBIEC, and HPV-BIEC cell lines had a mean doubling time of $14.16 \mathrm{~h}, 14.26 \mathrm{~h}, 13.33 \mathrm{~h}$, and $13.26 \mathrm{~h}$ respectively (Fig. 8b). There was no significant difference in the mean doubling time between BIECc4 cells and immortalized BIECs.

Analysis of TLR expression in early passage and immortalized BIECs

Two-step real-time RT-PCR was performed on the early passage BIEC-c4 cells and all three immortalized BIECs. Altogether, ten TLRs were tested for mRNA gene expression using specific primers, and $\mathrm{Ct}$ values were normalized using the housekeeping gene, HPRT-1 (Table 2). The mean Ct value and standard deviation for the housekeeping HPRT-1 gene in early passage BIEC-c4 cells was $23.53 \pm 0.45$. The mean $\mathrm{Ct}$ values for other three immortalized cell lines also did not vary significantly from BIEC-c4 cells. Primary and immortalized BIEC-c4 cells expressed all ten 


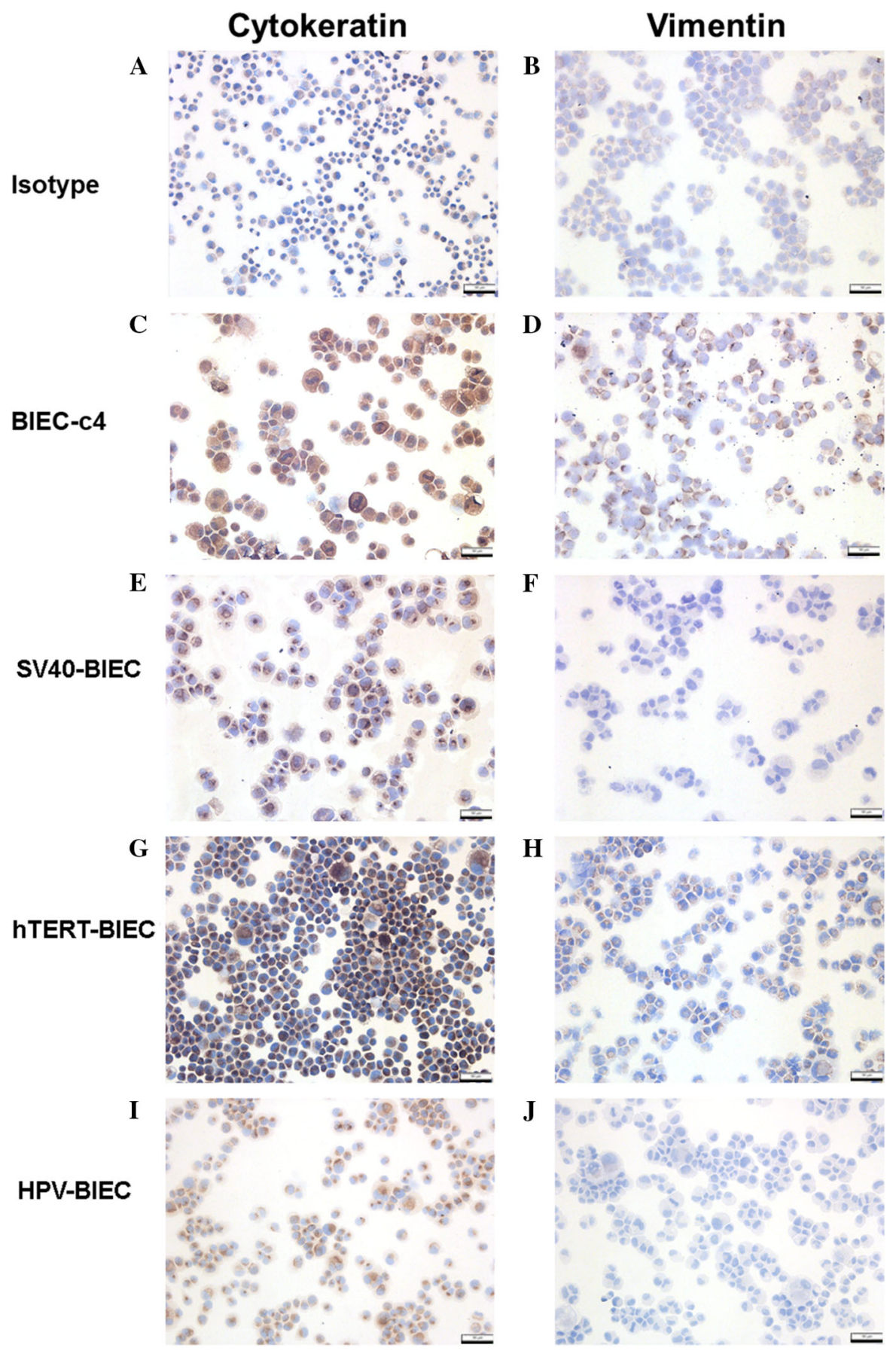

Fig. 4 Immunocytochemical staining for cytokeratin and vimentin. IgG2a isotype control staining in BIEC-c4 cells at passage 32 (a). Anti-cytokeratin IgG2a Ab staining in BIEC-c4 cells at passage 51 (c), SV40-BIECs at passage 53 (e), hTERTBIECs at passage $32(\mathrm{~g})$, and HPV-BIECs at passage 48 (i). IgM

TLRs (Fig. 9). Gene expression for each TLR was compared between early passage and immortalized isotype control staining in BIEC-c4 cells at passage 53 (b). Antivimentin IgM Ab staining in BIEC-c4 cells at passage 53 (d), SV40-BIECs at passage 53 (f), hTERT-BIECs at passage 30 (h), and HPV-BIECs at passage $48(\mathbf{j})$. Pictures were taken at $20 \times$ magnification and scale bar indicates $50 \mu \mathrm{m}$ length

cell types. There were no significant differences in gene expression among the early passage and 
A hTERT-BIEC

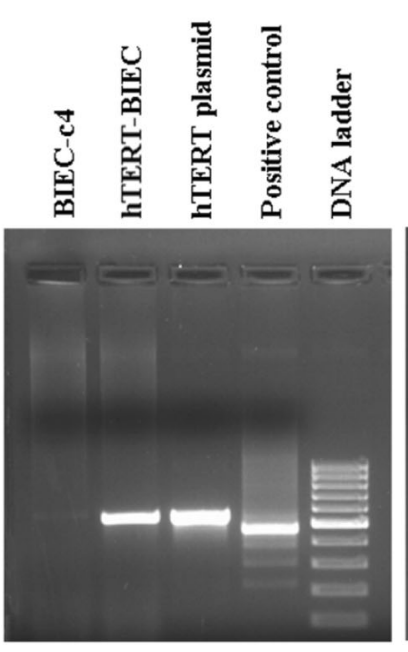

B SV40-BIEC

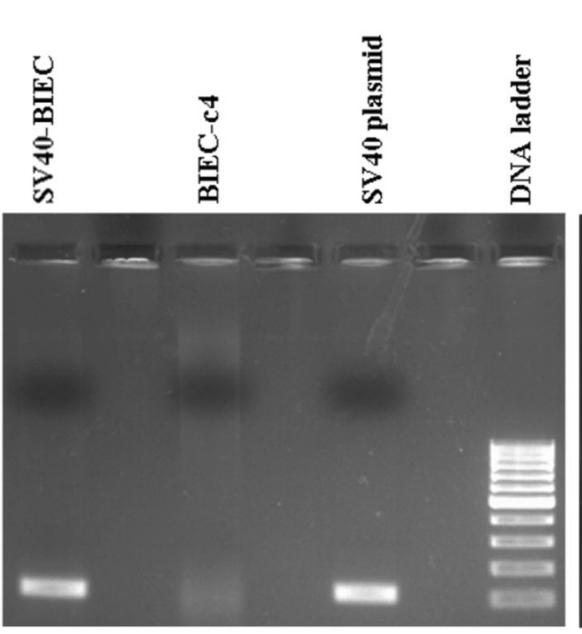

C HPV-BIEC

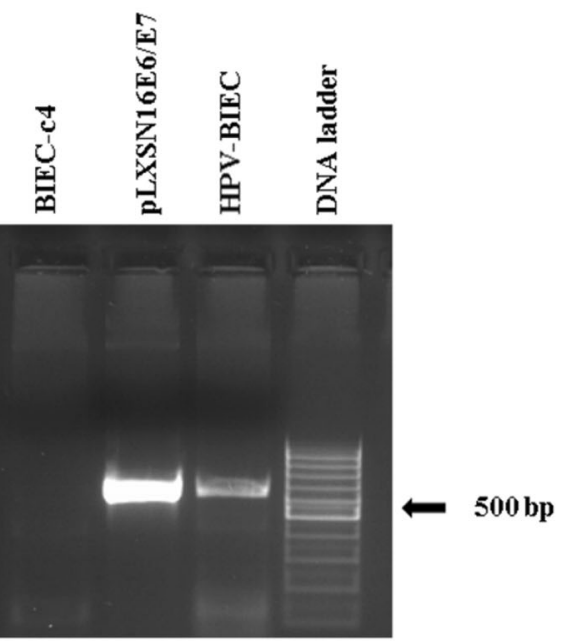

Fig. 5 PCR products for SV40, hTERT, and HPV genes. PCR was performed following DNA extraction from each of the three immortalized BIEC cell types (hTERT-BIEC at passage 30, SV40-BIEC at passage 48, and HPV-BIEC at passage 72) using primers specific to each gene (Table 1) and products were resolved on $1.5 \%$ agarose gel for the confirmation of hTERT gene in hTERT-BIEC DNA (a); SV40 gene in SV40-BIEC DNA (b); and E6/E7 gene in HPV-BIEC DNA (c)

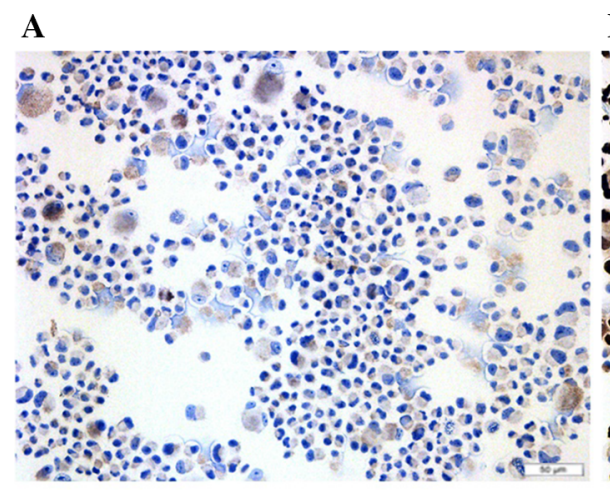

B

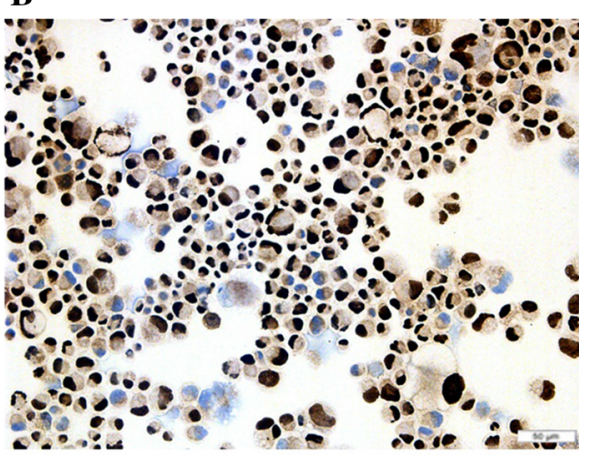

C

D

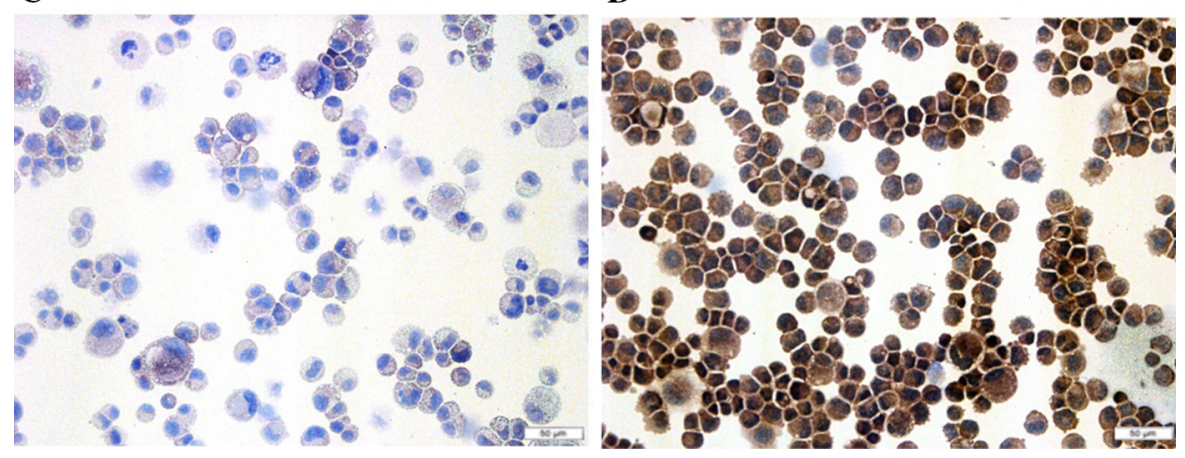

Fig. 6 Immunocytochemical staining for SV40 and hTERT proteins. BIEC-c4 cells at passage 61 (a) and SV40-BIECs at passage 58 (b) were stained for SV40 protein with mouse SV40specific monoclonal IgG2a Ab. BIEC-c4 cells at passage 34 (c) and hTERT-BIECs at passage 32 (d) were stained for hTERT protein with rabbit hTERT-specific polyclonal IgG Ab. Pictures were taken at $20 \times$ magnification and scale bar indicates $50 \mu \mathrm{m}$ length 

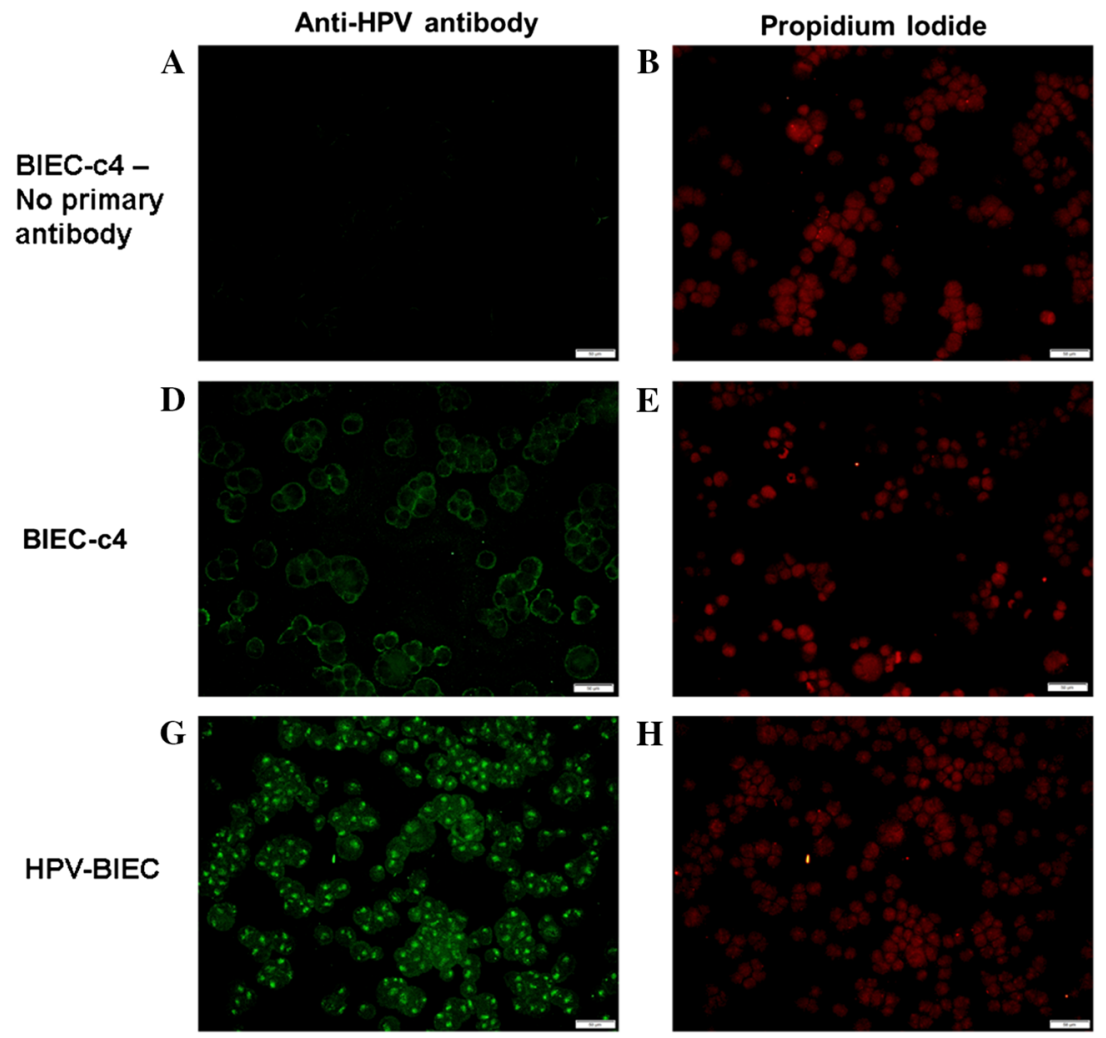

Fig. 7 Immunofluorescence staining for HPV E6 protein. a BIEC-c4 cells at passage 48 were stained with $1 \%$ chicken serum (no primary antibody control) and secondary antibody conjugated to Alexa 488. b BIEC-c4 cells (no primary antibody control); nuclei stained with propidium iodide. c BIEC-c4 cells (no primary antibody control); a, b merged picture. d BIEC-c4 cells were stained with HPV E6-specific primary antibody and secondary antibody conjugated to Alexa 488. e BIEC-c4 cells

immortalized BIEC-c4 for any of the TLRs tested. In general, TLRs 3 and 4 showed relatively strong expression, while TLRs 1,6 , and 10 showed relatively low expression for all four cell types (Fig. 9).

Maintenance of bovine intestinal epithelial cells by continuous culture

Early passage BIEC-c4 cells, SV40-BIECs, hTERTBIECs, and HPV-BIECs were each cultured in T25 flasks and were maintained by passaging them every 96 h. Supplemented DMEM/F12 media was replaced with fresh media every $48 \mathrm{~h}$ to maintain the normal cellular physiological conditions. All the four BIEC types were free of microbial contamination and retained their viability throughout the culture period. (with primary antibody); nuclei stained with propidium iodide. f BIEC-c4 cells (with primary antibody); d, e merged picture. g HPV-BIECs were stained with HPV E6-specific primary antibody and secondary antibody conjugated to Alexa 488. h HPV-BIECs; nuclei stained with propidium iodide. i HPVBIECs; $\mathbf{g}, \mathbf{h}$ merged picture. Pictures were taken at $20 \times$ magnification and scale bar indicates $50 \mu \mathrm{m}$ length

BIEC-c4, SV40-BIEC, hTERT-BIEC, and HPVBIEC cells were maintained in continuous cultures for $109,148,103$, and 106 passages respectively.

\section{Discussion}

Mixed bovine ileal epithelial and fibroblast-like cells established from a 2-day old calf in DMEM-2 up to passage 4 were cultured in supplemented DMEM/F12 medium for the enrichment of epithelial cells up to 8 passages. Pure epithelial cell clone designated as BIEC-c4 was established from passage 8 and characterized for the epithelial phenotype. Further, BIEC-c4 early passage cells were immortalized using SV40, hTERT, and HPV E6/E7 genes and were designated as 


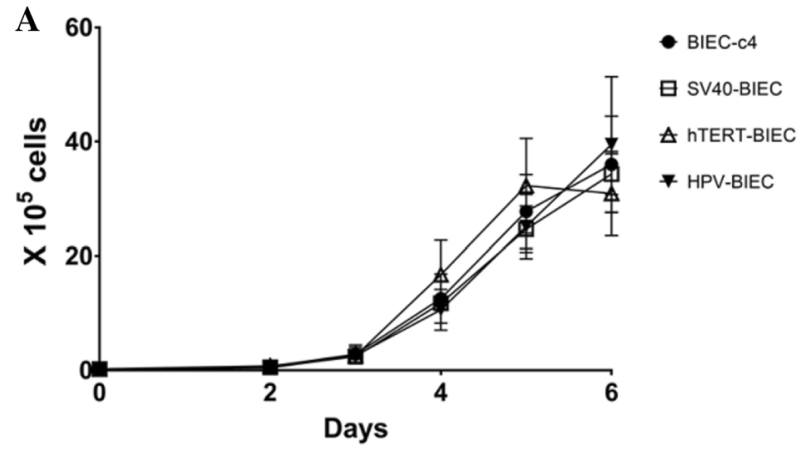

Fig. 8 Growth kinetics analysis of BIEC-c4 cells and immortalized BIECs. a Growth curve for BIEC-c4 (passage \# 51), SV40-BIEC (passage \# 90), hTERT-BIEC (passage \# 48), and HPV-BIEC (passage \# 48). On day 0, 20,000 cells were plated on five 6-well plates for each cell type. Beginning on day 2, until day 6 , cells were trypsinized every $24 \mathrm{~h}$ and counted using hemocytometer. b Analysis of doubling time for BIEC-c4 and

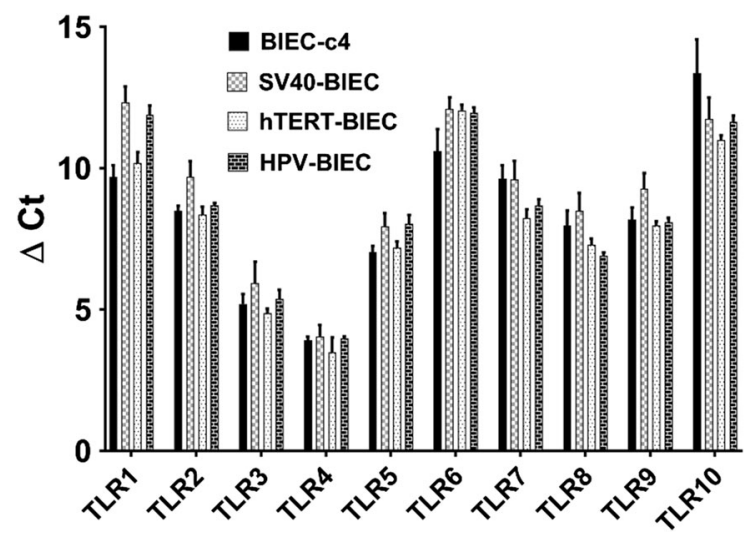

Fig. 9 TLRs 1-10 expression in BIEC-c4 cells (passages 5558) and immortalized BIECs. In this study, SV40-BIEC at passages 38-41, hTERT-BIEC at passages 32-36, and HPVBIEC at passages 44-47 were used. Expression levels of each TLR was compared among the four BIEC cell types. Change in cycle threshold, $\Delta \mathrm{Ct}$ was used to calculate gene expression for each TLR. $\Delta \mathrm{Ct}$ is calculated relative to HPRT-1 gene. $P$ value $<0.05$ was considered as statistically significant. Data presented as mean $\Delta \mathrm{Ct}$ from three independent experiments $(n=3)$ for each TLR. Bars represent standard error of the mean

SV40-BIEC, hTERT-BIEC, and HPV-BIEC cell lines respectively. These cell lines greatly expand the bovine intestinal invitrome (Bairoch 2018; Bols et al. 2017) and should have many uses depending on their properties.

Ultrastructure of intestinal epithelial cells show microvilli and tight junctions (Chopra et al. 2010; Miyazawa et al. 2010). When cultured on filter inserts,

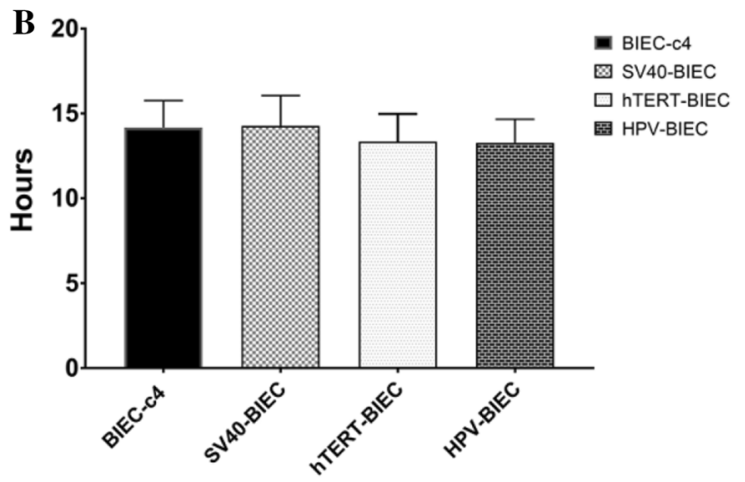

immortalized BIECs. Mean doubling time was calculated from three independent experiments $(n=3)$ for each cell type. Twotailed $t$ test was performed to compare mean doubling time between BIEC-c4 and each of the three immortalized BIECs. $P$ value $<0.05$ was considered as statistically significant. Bars represent standard error of the mean

intestinal epithelial cells have been reported to form tight junctions, as evident from the measurement of high TEER values (Johnson et al. 2010; Miyazawa et al. 2010). In this study, primary BIECs along with porcine intestinal epithelial cells (IPEC-J2) as a positive control were cultured on transwell-inserts for cell polarization and TEER readings were taken over a period of 7 days (Johnson et al. 2010). The BIEC-c4 cells did not show an increase in TEER values, confirming that polarization of cells did not occur. This may be attributed to the inability of BIECc4 cells to form tight junctions. The BIEC-c4 cells could be tested in further studies for the expression level of tight junction proteins (Anderson and Van Itallie 1995; Chaudhary et al. 2018; McNeil et al. 2006; Miyazawa et al. 2010). In an earlier study, fetalderived bovine duodenal epithelial cells not only showed high TEER values but also strongly expressed both zonula occludens-1 (ZO-1) and beta-catenin (Miyazawa et al. 2010). In corneal epithelial cells, ZO-1 protein had been shown to regulate epithelial phenotype and cell differentiation (Ryeom et al. 2000). It will be useful to evaluate the expression of tight junction proteins in response to specific soluble factors like cytokines or culture conditions which may enable the BIEC-c4 cells to get polarized.

Based on growth kinetics analysis, the three immortalized BIEC cell types established in this study did not show any significant differences in mean doubling time as compared to BIEC-c4 cells. All four 
BIEC cell lines were maintained continuously for more than 100 passages and at present, no other study has shown the ability of any primary BIECs to grow continuously for more than 100 passages (Loret et al. 2009). It is speculated that primary BIEC-c4 cells may have some stem cell-like characteristics, are less differentiated, and keep growing upon further passaging (Chopra et al. 2010). In future studies, the present BIEC cells may be cultured under different culture conditions in an attempt to differentiate them into a mature phenotype (Sanderson et al. 1996). These studies will provide the opportunity to investigate various factors or biological agents involved in intestinal cell differentiation and maturation. Thus, the primary BIECs cells established in this study would be of special interest and use in cell biology studies.

Due to the lack of species-specific homologous cell lines, various heterologous cell lines have been used for studying bovine enteric disease, innate immune response and pathogenesis (Bass et al. 1990; Kaushik et al. 2008; Lee et al. 1998). In vitro cell culture models derived from bovine intestinal epithelial cells have potential application in the evaluation of drug toxicity, immune regulation, and interaction with different enteric pathogens (Buckner et al. 2006; Chiba et al. 2012; Rusu et al. 2005; Takanashi et al. 2013; Villena et al. 2018). Jejunum and ileal cultures from bovine fetal tissues have been established and characterized for susceptibility to bovine rotavirus infection (Kaushik et al. 2008). However, this is the first study reporting the development of bovine intestinal epithelial cell lines from a 2-day old calf.

Several challenges are encountered in the isolation and generation of intestinal epithelial cell culture. The process is hindered greatly by the high rate of cell death occurring during isolation of the primary cells (Evans et al. 1994; Rusu et al. 2005). The disruption of extracellular matrix proteins (ECM) necessary for the cell to cell interaction leads to programmed cell death, a phenomenon called anoikis (Kaeffer 2002; Kaushik et al. 2008). Both enzymatic and non-enzymatic methods for isolation of epithelial cells have been used. A combination of mechanical and enzymatic methods using collagenase has been used by others to establish bovine cultures from jejunocytes and colonocytes derived from organoid preparations (Rusu et al. 2005). On the other hand, non-enzymatic, chelating methods using EDTA have also been used for epithelial cell isolation (Kaeffer 2002). While chelating methods are useful in the isolation of epithelial cells that retain their phenotypes, it has been found to affect cell surface receptors (Kaeffer 2002). Also, it is unable to maintain the cell to cell interactions (Kaeffer 2002; Kaushik et al. 2008). To overcome these difficulties, enzymatic methods are widely used today, as it is able to support the growth of crypt-like cells in organoids that can maintain epithelial phenotype (Kaushik et al. 2008; Rusu et al. 2005). In this study, collagenase and dispase enzymes were used for the digestion of epithelial cells from ileal tissues of the calf. Then for the maintenance of pure bovine intestinal epithelial cells in culture, trypsin-EDTA was used for passaging the cells upon confluency. Isolation processes, chiefly utilizing mechanical dissociation, lead to frequent contamination with fibroblasts (Rusu et al. 2005). A recent study demonstrating an improvement over the limiting dilution method for obtaining pure BIEC clones has also highlighted the problem of fibroblast contamination (Zhan et al. 2017). The growth of fibroblasts in cultures depends on the type of culture medium used, including supplementation with fetal bovine serum and trypsin-EDTA treatment (Kaushik et al. 2008). Studies seeking to elucidate the infectivity of intestinal epithelial cells with enteric pathogens can be affected by fibroblast growth in various ways. The study on bovine rotavirus infectivity showed that rotaviruses can infect fibroblasts, affecting the interpretation of results (Kaushik et al. 2008). The phenomenon of epithelial to mesenchymal phenotype transition has been observed in immortalized rat liver cell lines, simply by changing the culture medium from DMEM/ F12 to DMEM (Takenouchi et al. 2010).

Another impediment to the generation of a stable cell culture system is the limited proliferative capacity of primary cells in culture due to replicative senescence (Campisi 1996; Hayflick 1979). Very few studies have reported on the maintenance of primary culture for more than 10 generations (Kaeffer 2002; Loret et al. 2009). One of the major challenges is the difficulty in the isolation of intestinal epithelial crypts which affects the population of proliferating cells. Primary colonocytes and jejunocytes from both adult and fetal calves have been isolated and immortalized using SV40 large T antigen (Loret et al. 2009). These immortalized epithelial cells were cultured for 50 passages and were able to retain the epithelial 
phenotype, while the untreated primocultures were only maintained for 7 passages (Loret et al. 2009). Ovine endometrial cell lines immortalized with HPV E6/E7 genes were also shown to retain original cell phenotype (Johnson et al. 1999). Human cytotrophoblast cells and bovine mammary gland epithelial cells (bMGEs) immortalized with hTERT gene not only showed enhanced lifespan but also retained original parental phenotype (He et al. 2011; Wang et al. 2006).

Transfection reagents used to transfect plasmid DNA containing immortalization genes could influence the transfection efficiency. Lipid-based Lipofectamine reagent used in this study was shown to have a transfection efficiency of $12-22 \%$ in mouse embryonic fibroblast (MEF) cells (Lee et al. 2017). In another study, bovine mammary epithelial alveolar (MACT) cells showed transfection efficiency of 16.3\%, while Madin Darby Bovine Kidney (MDBK) cells showed an efficiency of $2.2 \%$ (Osorio and Bionaz 2017). It is critical that the selected transfection method does not affect normal cellular characteristics. Transfection reagents have been evaluated for toxicity and activation of cellular stress responses (FiszerKierzkowska et al. 2011; Masotti et al. 2009). More importantly, the transfection efficiency can be affected by cell type, passage number, cell density, and the amount of plasmid DNA transfected (Dalby et al. 2004; Lee et al. 2017). In this study, we transfected BIEC-c4 cells with Lipofectamine 2000 reagent. The BIEC-c4 cells at different passages were transfected with SV40, hTERT, and HPV E6/E7 genes respectively to establish three immortalized BIEC cell lines. We confirmed by PCR the expression of desired plasmids in the three immortalized BIECs. These cells also expressed the SV40, hTERT, and HPV E6 gene products. The detection of SV40 LT Ag, hTERT and HPV E6 proteins in the immortalized BIECs was done at late passages 58, 32, and 48 respectively.

Various studies have shown alterations in glycosylation pattern in immortalized cell lines as compared to normal cells. Intestinal epithelial cells express various sugar residues, chiefly $\mathrm{N}$-acetylglucosamine (GlcNAc), galactose (Gal), N-acetylgalactosamine (GalNAc), fucose, $\mathrm{N}$-acetylneuraminic acid and sialic acid (Freitas et al. 2005). Lectin binding profile of porcine intestinal tissue for the expression of carbohydrate moieties has been reported (George et al. 2007). Many carbohydrate moieties serve as a receptor for binding and subsequent entry of pathogens to initiate infection (Kato and Ishiwa 2015). Sialic acid and heparan sulfate are used as receptors by many viruses (Kato and Ishiwa 2015; Mestecky 2005). Members of the Paramyxovirus family, Rotaviruses, Coronaviruses and Influenza viruses (A, B and C), bind to sialoglycoconjugate receptors on host cell surface (Mestecky 2005). Immortalized ras-MDCK cells showed increased cell surface fucosylation while showing a decrease in O-linked glycans and sialylation (Bruyneel et al. 1990). In another study, human stromal cells immortalized with hTERT gene showed increased galactosylation (Kuwahara et al. 2003). Therefore, in future studies, it will be useful to study if immortalization process changes the expression of carbohydrates on BIEC cell surface. Furthermore, as all the three immortalized cells lines in this study were derived from the primary BIEC-c4 cells, these cells can be effectively used to study the physiological, biochemical and immunological changes various immortalization methods may induce in these cells.

Studies on the characterization of bovine intestinal epithelial cells have revealed important morphological and biochemical characteristics of cultured intestinal epithelial cells. The epithelial tissue is in close association with fibroblasts, also called endodermal structural proliferative units (Kaeffer 2002). Epithelial cells are characterized by the expression of the protein cytokeratin, while cells of mesenchymal origins, chiefly fibroblasts, express vimentin (Kaeffer 2002; Rusu et al. 2005). Cytokeratin is a protein of intermediate filaments found within the cytoskeletal regions of epithelial cells (Kaeffer 2002). Cytokeratins (CK) can be grouped into two types: type I (acidic) which includes cytokeratins CK9-CK20 and type II (neutralbasic) which includes CK1-CK8 (Weng et al. 2012). Cytokeratin expression has been found to be tissuespecific (Chu and Weiss 2002). Epithelial cells express cytokeratins in different combinations which may be dependent on cellular differentiation level or certain cellular characteristics (Moll 1991). Detailed cellular and molecular characterization of cytokeratins in bovine tissues have been reported by others (Blessing et al. 1987; Hu et al. 2009; Paladino et al. 2004). The established BIEC-c4 clone and the three immortalized BIEC cell lines all expressed cytokeratin, with low levels of vimentin expression. Analysis of gene transcripts and western blot have demonstrated that bovine and porcine epithelial cells in culture can co- 
express cytokeratin and vimentin (Kaushik et al. 2008; Rusu et al. 2005; Sun et al. 2012). Fetal-derived bovine intestinal epithelial cells in culture were found to express both cytokeratin and vimentin, and the percentage of cells expressing vimentin increased with further passaging (Kaushik et al. 2008). However, only epithelial cells express cytokeratin protein which is absent in fibroblasts. One possibility for the expression of mesenchymal phenotype is contamination with mesenchymal cells (Kaushik et al. 2008; Rusu et al. 2005). More importantly, primary enterocytes in culture can undergo a process of de-differentiation, whereby they lose certain epithelial phenotype (Rusu et al. 2005). Also, the inability to select epithelial crypts could favor the proliferation of mesenchymal cells as compared to epithelial cells (Rusu et al. 2005). Usually, mesenchymal cells express both vimentin and $\alpha$-smooth muscle actin ( $\alpha$-SMA). However, the BIEC-c4 and the immortalized cells were negative for $\alpha$-SMA, which is a marker of smooth muscle cells. Therefore, the BIECs established in this study were pure epithelial cells, devoid of mesenchymal contamination. We performed morphological and phenotypic characterization of BIECs at passages varying from 19 to 58 . The BIEC-c4 cells at passage 51 showed strong cytokeratin expression, as evident from ICC staining. We also confirmed the expression of epithelial phenotype in the three immortalized BIECs at different passages. Cytokeratin protein was expressed in SV40, hTERT, and HPV immortalized BIECs at passages 53, 32, and 48 respectively. Therefore, immortalization did not affect the epithelial phenotype for the cell passages studied. Study of both epithelial phenotype in BIEC-c4 and the expression of SV40, hTERT, and HPV proteins in the immortalized BIECs at late passages is important to demonstrate stable expression of the desired phenotypes.

Characterization of PRRs on bovine tissues has provided important knowledge on innate immune responses. A variety of cells including macrophages, dendritic cells, and intestinal epithelial cells have been shown to express TLRs (Charavaryamath et al. 2011; Turin and Riva 2008; Werling et al. 2006). The published partial sequences of bovine TLRs 1-10 have been found to share homology with ovine TLRs (Werling et al. 2006). Recently, much of the work on bovine TLRs has focused on elucidating its role in mediating innate immune responses. Mutations and polymorphism studies have revealed a difference in bovine TLRs which could have implications in the selection of cattle breeds resistant to diseases (Fisher et al. 2011; Werling et al. 2006). Analyses of TLR mRNA transcripts in eight different bovine antigenpresenting cell subsets have revealed differences in TLR mRNA expression level among the different subsets (Werling et al. 2006). Bovine macrophage subsets differ in innate immune response against various mycobacterium species (Werling et al. 2006). In this present study, primary cultures of BIECs were characterized for the expression of TLR mRNA transcripts (TLRs 1-10) using two-step real-time RTPCR. The expression level of each TLR mRNA was compared among the four BIEC cell types. BIEC-c4 and immortalized BIEC-c4 cells expressed all ten TLRs and showed no significant differences in TLR expression as assessed by Wilcoxon-signed-rank test. This indicates that immortalization did not change the TLR expression of normal BIEC-c4 cells. Therefore, expression of TLR genes suggests that BIEC-c4 cells may be a good model to study innate immune response against various enteric pathogens.

Studies on TLR mediated immune responses have revealed important applications of bovine intestinal epithelial cells. Study of innate immune responses can provide important knowledge for the development of adjuvants and immunobiotics (Buckner et al. 2006; Villena et al. 2018; Werling et al. 2006). Fetal-derived, early passage BIECs have been used in screening assays for the identification of new adjuvants, based on the stimulation of IL-8 cytokine, and also supported rotavirus infection (Buckner et al. 2006). Fetalderived bovine intestinal epithelial cells (BIECs) immortalized with SV40 LT Ag were used to study the immunomodulatory effects of lactic acid bacteria (LAB) upon challenge with enterotoxigenic E. coli (ETEC) (Takanashi et al. 2013). These BIECs were characterized for the expression of all ten TLRs and were found to strongly express TLRs 1, 3, 4 and 6 (Takanashi et al. 2013). Also, increased expression levels of proinflammatory cytokines IL-1, IL-6 and IL8 were observed (Takanashi et al. 2013). In another study, bovine intestinal epithelial cells were investigated for TLR mediated immune response against $C$. parvum infection (Yang et al. 2015). However, in this study, we not only generated BIEC clones but also studied if immortalization changed TLR expression in BIECs. We found a higher expression of TLRs 3 and 4 
across all four BIEC cell types as compared to other TLRs. TLR3 may play an important role during bovine enteric viral infections, chiefly BRV (Aich et al. 2007). Likewise, TLR4 may be important for both pathogen recognition as well as maintenance of immune homeostasis in the intestinal epithelium (Villena et al. 2014). In the future, the TLRs expressed by BIEC cells may be stimulated with TLR specific ligands or challenged with different enteric pathogens to study innate immune responses. Further investigation on this may reveal more information about the role of TLRs in BIECs. Therefore, the established BIEC cell lines may serve as a useful model system to study host-pathogen interaction and regulation of immune responses.

The ability to generate clones from a single cell is typically a characteristic of stem cell-like cells or tumor cells. Using limiting dilution method, we successfully generated a pure BIEC clone from a single cell. Immortalization of mixed epithelial-like cells followed by limiting dilution is the usual approach since single cell suspension may fail to generate clones unless those have been immortalized. In a previous study, limiting dilution was first performed to obtain fetal-derived pure BIEC culture. However, it was immortalized with SV40 gene after a few passages due to a decline in cell proliferative capacity (Miyazawa et al. 2010). These cells were shown to form tight junctions (Miyazawa et al. 2010). In this study, we first generated a stable BIEC-c4 clone and then immortalized it with three different methods. All four cell types retained their ability to proliferate and were maintained by continuous culture. The possibility that the BIEC-c4 clone was obtained from a stem cell-like population cannot be ruled out (Peterson and Artis 2014; Potten et al. 1997). For instance, the mixed ileal epithelial-like cells could have been derived from crypt-resident stem cells (Booth and Potten 2000). Additionally, we were not able to polarize the BIEC-c4 culture, which may be due to the less differentiated phenotype of the BIECc4 cells, suggesting that these are more stem cell-like. The BIEC clone generated by limiting dilution could, however, change to a more differentiated phenotype during passaging and lose its ability to proliferate. Therefore, immortalization was necessary. Further, it would also be difficult to characterize the pure BIEC clones if those were immortalized prior to limiting dilution as immortalization could change certain phenotypes. Also, it would be difficult to identify whether the proliferative capacity of BIECs was dependent on or independent of immortalization. As a result, we were able to identify the ability of BIECclones to grow in continuous culture to be independent of immortalization. In the future, immortalized BIECc4 clones may be cultured under different culture conditions to differentiate into a more mature phenotype. Due to the trade-off between cell proliferation and differentiation, immortalization may be able to rescue the BIECs from loss of proliferation.

In conclusion, the bovine intestinal epithelial cell line, designated as BIEC-c4, and the immortalized BIECs were established and characterized using different immunological and biochemical techniques. The established primary and the immortalized BIECs may be further investigated for TLR mediated immune responses. Further studies may clarify and justify the effective use of these cells for studying the innate immune responses against enteric pathogens.

Acknowledgements Radhey S. Kaushik, Pratik Katwal, Tirth Uprety, and Milton Thomas, and this research project were funded and supported by USDA, NIFA, SDSU Agricultural Experiment Station Hatch Grants \# SD00H326-09, and SD00H547-15. This study was also funded by USDA/ CSREES through project title JDIP: Johne's Disease Integrated Program in Research, Education, and Extension, Grant Number \# 2004-35605-14243; Sub-award No. Q6286224171. We acknowledge use of the SDSU-FGCF supported in part by NSF/EPSCoR Grant No. 0091948 and by the State of South Dakota.

Authors' Contributions RSK conceived and designed the study, received funding, and also conducted some of the experiments. RSK also reviewed the manuscript. PK, MT, and TU (graduate researchers) conducted the experiments, analyzed the results and wrote the paper. $\mathrm{MH}$ contributed to reagents/materials, analysis and helped in microscopy.

\section{Compliance with ethical standards}

Conflict of interest The authors declare no conflict of interest.

\section{References}

Aich P, Wilson HL, Kaushik RS, Potter AA, Babiuk LA, Griebel $\mathrm{P}$ (2007) Comparative analysis of innate immune responses following infection of newborn calves with bovine rotavirus and bovine coronavirus. J Gen Virol 88:2749-2761. https://doi.org/10.1099/vir.0.82861-0 
Akira S, Uematsu S, Takeuchi O (2006) Pathogen recognition and innate immunity. Cell 124:783-801. https://doi.org/10. 1016/j.cell.2006.02.015

Anderson JM, Van Itallie CM (1995) Tight junctions and the molecular basis for regulation of paracellular permeability. Am J Physiol 269:G467-G475. https://doi.org/10.1152/ ajpgi.1995.269.4.G467

Bairoch A (2018) The cellosaurus, a cell-line knowledge resource. J Biomol Tech JBT 29:25-38. https://doi.org/10. 7171/jbt.18-2902-002

Bass DM, Mackow ER, Greenberg HB (1990) NS35 and not vp7 is the soluble rotavirus protein which binds to target cells. J Virol 64:322-330

Birkner S, Weber S, Dohle A, Schmahl G, Follmann W (2004) Growth and characterisation of primary bovine colon epithelial cells in vitro. Altern Lab Anim ATLA 32:555-571

Blessing M, Zentgraf H, Jorcano JL (1987) Differentially expressed bovine cytokeratin genes: analysis of gene linkage and evolutionary conservation of $5^{\prime}$-upstream sequences. EMBO J 6:567-575

Bodnar AG et al (1998) Extension of life-span by introduction of telomerase into normal human cells. Science 279:349-352

Bols NC, Pham PH, Dayeh VR, Lee LEJ (2017) Invitromatics, invitrome, and invitroomics: introduction of three new terms for in vitro biology and illustration of their use with the cell lines from rainbow trout. In Vitro Cell Dev Biol Anim 53:383-405. https://doi.org/10.1007/s11626-0170142-5

Booth C, Potten CS (2000) Gut instincts: thoughts on intestinal epithelial stem cells. J Clin Investig 105:1493-1499

Booth C, Patel S, Bennion GR, Potten CS (1995) The isolation and culture of adult mouse colonic epithelium. Epithel Cell Biol 4:76-86

Booth C, O'Shea JA, Potten CS (1999) Maintenance of functional stem cells in isolated and cultured adult intestinal epithelium. Exp Cell Res 249:359-366. https://doi.org/10. 1006/excr.1999.4483

Bruyneel EA, Debray H, De Mets M, Mareel MM, Montreuil J (1990) Altered glycosylation in Madin-Darby canine kidney (MDCK) cells after transformation by murine sarcoma virus. Clin Exp Metastasis 8:241-253

Buckner D, Wilson S, Kurk S, Hardy M, Miessner N, Jutila MA (2006) Use of early passage fetal intestinal epithelial cells in semi-high-throughput screening assays: an approach to identify new innate immune system adjuvants. J Biomol Screen 11:664-671. https://doi.org/10.1177/ 1087057106289876

Campisi J (1996) Replicative senescence: an old lives' tale? Cell 84:497-500. https://doi.org/10.1016/S00928674(00)81023-5

Cencič A, Langerholc T (2010) Functional cell models of the gut and their applications in food microbiology: a review. Int $\mathrm{J}$ Food Microbiol 141:S4-S14. https://doi.org/10.1016/j. ijfoodmicro.2010.03.026

Cencic A, Gradinik L, Vaukner M, Filipi B, Rannou O, Chingwaru W, Maragkoudakis P, Tsakalidou E (2007) Lefevre $\mathrm{F}$ intestinal cell models as alternative to experimental animals in research of food and water born viruses interactions with the host. Exp Pathol Health Sci 1:57
Charavaryamath C et al (2011) Mucosal changes in a long-term bovine intestinal segment model following removal of ingesta and microflora. Gut Microbes 2:134-144. https:// doi.org/10.4161/gmic.2.3.16483

Chaudhary N, Agrawal H, Pandey M, Onteru S, Singh D (2018) Development and characterization of 2-dimensional culture for buffalo intestinal cells. Cytotechnology 70:361-373. https://doi.org/10.1007/s10616-017-0151-y

Chen WH et al (2006) Tissue engineered cartilage using human articular chondrocytes immortalized by HPV-16 E6 and E7 genes. J Biomed Mater Res, Part A 76:512-520. https://doi. org/10.1002/jbm.a.30560

Chiba E et al (2012) A newly established bovine intestinal epithelial cell line is effective for in vitro screening of potential antiviral immunobiotic microorganisms for cattle. Res Vet Sci 93:688-694. https://doi.org/10.1016/j.rvsc. 2011.10.002

Cho YI, Yoon KJ (2014) An overview of calf diarrhea: infectious etiology, diagnosis, and intervention. J Vet Sci 15:1-17

Chopra DP, Dombkowski AA, Stemmer PM, Parker GC (2010) Intestinal epithelial cells in vitro. Stem Cells Dev 19:131-142. https://doi.org/10.1089/scd.2009.0109

Chu PG, Weiss LM (2002) Keratin expression in human tissues and neoplasms. Histopathology 40:403-439

Dalby B, Cates S, Harris A, Ohki EC, Tilkins ML, Price PJ, Ciccarone VC (2004) Advanced transfection with Lipofectamine 2000 reagent: primary neurons, siRNA, and high-throughput applications. Methods 33:95-103. https:// doi.org/10.1016/j.ymeth.2003.11.023

Evans GS, Flint N, Potten CS (1994) Primary cultures for studies of cell regulation and physiology in intestinal epithelium. Annu Rev Physiol 56:399-417. https://doi.org/10.1146/ annurev.ph.56.030194.002151

Fisher CA et al (2011) Evolution of the bovine TLR gene family and member associations with mycobacterium avium subspecies paratuberculosis infection. PLoS ONE 6:e27744. https://doi.org/10.1371/journal.pone.0027744

Fiszer-Kierzkowska A, Vydra N, Wysocka-Wycisk A, Kronekova Z, Jarzab M, Lisowska KM, Krawczyk Z (2011) Liposome-based DNA carriers may induce cellular stress response and change gene expression pattern in transfected cells. BMC Mol Biol 12:27. https://doi.org/10.1186/14712199-12-27

Foster DM, Smith GW (2009) Pathophysiology of diarrhea in calves. Vet Clin N Am Food Anim Pract 25:xi. https://doi. org/10.1016/j.cvfa.2008.10.013

Freitas M, Axelsson LG, Cayuela C, Midtvedt T, Trugnan G (2005) Indigenous microbes and their soluble factors differentially modulate intestinal glycosylation steps in vivo: use of a "lectin assay" to survey in vivo glycosylation changes. Histochem Cell Biol 124:423-433. https://doi. org/10.1007/s00418-005-0004-1

Freshney RI (1994) Culture of animal cells: a manual of basic technique, 3rd edn. Wiley, New York

Geens MM, Niewold TA (2011) Optimizing culture conditions of a porcine epithelial cell line IPEC-J2 through a histological and physiological characterization. Cytotechnology 63:415-423. https://doi.org/10.1007/s10616-011-9362-9

George $S$ et al (2007) Lectin binding profile of the small intestine of five-week-old pigs in response to the use of 
chlortetracycline as a growth promotant and under gnotobiotic conditions. J Anim Sci 85:1640-1650. https://doi. org/10.2527/jas.2006-662

Hayflick L (1979) The cell biology of aging. J Investig Dermatol 73:8-14. https://doi.org/10.1111/1523-1747.ep12532752

He XY et al (2011) Recombinant adenovirus-mediated human telomerase reverse transcriptase gene can stimulate cell proliferation and maintain primitive characteristics in bovine mammary gland epithelial cells. Dev Growth Differ 53:312-322. https://doi.org/10.1111/j.1440-169X.2010. 01236.x

Hu H, Wang J, Bu D, Wei H, Zhou L, Li F, Loor JJ (2009) Vitro culture and characterization of a mammary epithelial cell line from chinese holstein dairy cow. PLoS ONE 4:e7636. https://doi.org/10.1371/journal.pone.0007636

Iwasaki A, Medzhitov R (2010) Regulation of adaptive immunity by the innate immune system. Science 327:291-295. https://doi.org/10.1126/science.1183021

Janeway CA Jr (1989) Approaching the asymptote? Evolution and revolution in immunology. Cold Spring Harb Symp Quant Biol 54:1-13

Janeway CA Jr, Medzhitov R (2002) Innate immune recognition. Ann Rev Immunol 20:197-216. https://doi.org/10. 1146/annurev.immunol.20.083001.084359

Jin $M$ et al (2004) Investigation of simian virus 40 large $T$ antigen in 18 autopsied malignant mesothelioma patients in Japan. J Med Virol 74:668-676. https://doi.org/10.1002/ jmv.20219

Johnson GA, Burghardt RC, Newton GR, Bazer FW, Spencer TE (1999) Development and characterization of immortalized ovine endometrial cell lines. Biol Reprod 61:1324-1330

Johnson AM, Kaushik RS, Hardwidge PR (2010) Disruption of transepithelial resistance by enterotoxigenic Escherichia coli. Vet Microbiol 141:115-119. https://doi.org/10.1016/ j.vetmic.2009.08.020

Kaeffer B (2002) Mammalian intestinal epithelial cells in primary culture: a mini-review. In Vitro Cell Dev Biol Anim 38:123-134. https://doi.org/10.1290/10712690(2002)038\%3c0123:MIECIP\%3e2.0.CO;2

Kaeffer B, Bottreau E, Velge P, Pardon P (1993) Epithelioid and fibroblastic cell lines derived from the ileum of an adult histocompatible miniature boar (d/d haplotype) and immortalized by SV40 plasmid. Eur J Cell Biol 62:152-162

Kato K, Ishiwa A (2015) The role of carbohydrates in infection strategies of enteric pathogens. Trop Med Health 43:41-52. https://doi.org/10.2149/tmh.2014-25

Kaushik RS et al (2008) Establishment of fetal bovine intestinal epithelial cell cultures susceptible to bovine rotavirus infection. J Virol Methods 148:182-196. https://doi.org/ 10.1016/j.jviromet.2007.11.006

Khare S et al (2009) Early phase morphological lesions and transcriptional responses of bovine ileum infected with Mycobacterium avium subsp. paratuberculosis. Vet Pathol 46:717-728. https://doi.org/10.1354/vp.08-VP-0187-G-FL

Koh SY, George S, Brozel V, Moxley R, Francis D, Kaushik RS (2008) Porcine intestinal epithelial cell lines as a new in vitro model for studying adherence and pathogenesis of enterotoxigenic Escherichia coli. Vet Microbiol
130:191-197. https://doi.org/10.1016/j.vetmic.2007.12. 018

Kuwahara I et al (2003) Changes in N-glycosylation of human stromal cells by telomerase expression. Biochem Biophys Res Commun 301:293-297

Lee J, Yoo D, Redmond MJ, Attah-Poku SK, van den Hurk JV, Babiuk LA (1998) Characterization of the interaction between VP8 of bovine rotavirus $\mathrm{C} 486$ and cellular components on MA-104 cells and erythrocytes. Can J Vet Res 62:56-62

Lee M, Chea K, Pyda R, Chua M, Dominguez I (2017) Comparative analysis of non-viral transfection methods in mouse embryonic fibroblast cells. J Biomol Tech JBT 28:67-74. https://doi.org/10.7171/jbt.17-2802-003

Loret S, Rusu D, El Moualij B, Taminiau B, Heinen E, Dandrifosse G, Mainil J (2009) Preliminary characterization of jejunocyte and colonocyte cell lines isolated by enzymatic digestion from adult and young cattle. Res Vet Sci 87:123-132. https://doi.org/10.1016/j.rvsc.2008.12.002

Masotti A et al (2009) Comparison of different commercially available cationic liposome-DNA lipoplexes: parameters influencing toxicity and transfection efficiency. Colloids Surf B Biointerfaces 68:136-144. https://doi.org/10.1016/ j.colsurfb.2008.09.017

Maynard CL, Elson CO, Hatton RD, Weaver CT (2012) Reciprocal interactions of the intestinal microbiota and immune system. Nature 489:231-241

McNeil E, Capaldo CT, Macara IG (2006) Zonula occludens-1 function in the assembly of tight junctions in Madin-Darby canine kidney epithelial cells. Mol Biol Cell 17:1922-1932. https://doi.org/10.1091/mbc.E05-07-0650

Medzhitov R, Janeway CA Jr (1997) Innate immunity: the virtues of a nonclonal system of recognition. Cell 91:295-298

Menzies M, Ingham A (2006) Identification and expression of Toll-like receptors 1-10 in selected bovine and ovine tissues. Vet Immunol Immunopathol 109:23-30. https://doi. org/10.1016/j.vetimm.2005.06.014

Mestecky J (2005) Mucosal immunology, 3rd edn. Elsevier Academic Press, Boston

Miyake K (2007) Innate immune sensing of pathogens and danger signals by cell surface Toll-like receptors. Semin Immunol 19:3-10. https://doi.org/10.1016/j.smim.2006. 12.002

Miyazawa K et al (2010) Characterization of newly established bovine intestinal epithelial cell line. Histochem Cell Biol 133:125-134. https://doi.org/10.1007/s00418-009-0648-3

Mogensen TH (2009) Pathogen recognition and inflammatory signaling in innate immune defenses. Clin Microbiol Rev 22:240-273. https://doi.org/10.1128/CMR.00046-08

Mohler VL, Izzo MM, House JK (2009) Salmonella in calves. Vet Clin N Am Food Anim Pract 25:37-54. https://doi.org/ 10.1016/j.cvfa.2008.10.009

Moll R (1991) Molecular diversity of cytokeratins: significance for cell and tumor differentiation. Acta Histochem Suppl 41:117-127

Osorio JS, Bionaz M (2017) Plasmid transfection in bovine cells: optimization using a realtime monitoring of green fluorescent protein and effect on gene reporter assay. Gene 626:200-208. https://doi.org/10.1016/j.gene.2017.05.025

Paladino G, Marino C, La Terra Mulè S, Civiale C, Rusciano D, Enea V (2004) Cytokeratin expression in primary epithelial 
cell culture from bovine conjunctiva. Tissue Cell 36:323-332. https://doi.org/10.1016/j.tice.2004.05.003

Peterson LW, Artis D (2014) Intestinal epithelial cells: regulators of barrier function and immune homeostasis. Nat Rev Immunol 14:141-153. https://doi.org/10.1038/nri3608

Potten CS, Booth C, Pritchard DM (1997) The intestinal epithelial stem cell: the mucosal governor. Int J Exp Pathol 78:219-243

Rakoff-Nahoum S, Paglino J, Eslami-Varzaneh F, Edberg S, Medzhitov R (2004) Recognition of commensal microflora by Toll-like receptors is required for intestinal homeostasis. Cell 118:229-241. https://doi.org/10.1016/j.cell.2004. 07.002

Rings DM (2004) Clostridial disease associated with neurologic signs: tetanus, botulism, and enterotoxemia. Vet Clin N Am Food Anim Pract 20:379-391. https://doi.org/10.1016/ j.cvfa.2004.02.006

Rusu D, Loret S, Peulen O, Mainil J, Dandrifosse G (2005) Immunochemical, biomolecular and biochemical characterization of bovine epithelial intestinal primocultures. BMC Cell Biol 6:42. https://doi.org/10.1186/1471-2121-642

Ryeom SW, Paul D, Goodenough DA (2000) Truncation mutants of the tight junction protein ZO-1 disrupt corneal epithelial cell morphology. Mol Biol Cell 11:1687-1696

Sanderson IR et al (1996) Human fetal enterocytes in vitro: modulation of the phenotype by extracellular matrix. Proc Natl Acad Sci USA 93:7717-7722

Schaeffer WI (1990) Terminology associated with cell, tissue, and organ culture, molecular biology, and molecular genetics. Tissue culture association terminology committee. In Vitro Cell Dev Biol 26:97-101

Steube KG, Koelz AL, Uphoff CC, Drexler HG, Kluess J, Steinberg P (2012) The necessity of identity assessment of animal intestinal cell lines: a case report. Cytotechnology 64:373-378. https://doi.org/10.1007/s10616-011-9420-3

Sun $\mathrm{Z}$ et al (2012) Characterization of a porcine intestinal epithelial cell line for influenza virus production. J Gen Virol 93:2008-2016. https://doi.org/10.1099/vir.0.044388-0

Takanashi N et al (2013) Advanced application of bovine intestinal epithelial cell line for evaluating regulatory effect of lactobacilli against heat-killed enterotoxigenic Escherichia coli-mediated inflammation. BMC Microbiol 13:54. https://doi.org/10.1186/1471-2180-13-54

Takenouchi T, Yoshioka M, Yamanaka N, Kitani H (2010) Reversible conversion of epithelial and mesenchymal phenotypes in SV40 large T antigen-immortalized rat liver cell lines. Cell Biol Int Rep 17:e00001. https://doi.org/10. 1042/CBR20100001

Thomas $\mathrm{M}$ et al (2018) Comparison of porcine airway and intestinal epithelial cell lines for the susceptibility and expression of pattern recognition receptors upon influenza virus infection. Viruses 10:312. https://doi.org/10.3390/ v10060312

Turin L, Riva F (2008) Toll-like receptor family in domestic animal species. Crit Rev Immunol 28:513-538

Vidrich A, Ravindranath R, Farsi K, Targan S (1988) A method for the rapid establishment of normal adult mammalian colonic epithelial cell cultures. In Vitro Cell Dev Biol 24:188-194

Villena J, Aso H, Kitazawa H (2014) Regulation of Toll-like receptors-mediated inflammation by immunobiotics in bovine intestinal epitheliocytes: role of signaling pathways and negative regulators. Front Immunol 5:421. https://doi. org/10.3389/fimmu.2014.00421

Villena J, Aso H, Rutten V, Takahashi H, van Eden W, Kitazawa $H$ (2018) Immunobiotics for the bovine host: their interaction with intestinal epithelial cells and their effect on antiviral immunity. Front Immunol 9:326. https://doi.org/ 10.3389/fimmu.2018.00326

Wang X, Moutsoglou D (2009) Osteogenic and adipogenic differentiation potential of an immortalized fibroblast-like cell line derived from porcine peripheral blood. In Vitro Cell Dev Biol Anim 45:584-591. https://doi.org/10.1007/ s11626-009-9231-4

Wang YL et al (2006) Immortalization of normal human cytotrophoblast cells by reconstitution of telomeric reverse transcriptase activity. Mol Hum Reprod 12:451-460. https://doi.org/10.1093/molehr/gal054

Weng YR, Cui Y, Fang JY (2012) Biological functions of cytokeratin 18 in cancer. Mol Cancer Res MCR 10:485-493. https://doi.org/10.1158/1541-7786.mcr-110222

Werling D, Jungi TW (2003) Toll-like receptors linking innate and adaptive immune response. Vet Immunol Immunopathol 91:1-12

Werling D, Piercy J, Coffey TJ (2006) Expression of Toll-like receptors (TLR) by bovine antigen-presenting cells-potential role in pathogen discrimination? Vet Immunol Immunopathol 112:2-11. https://doi.org/10.1016/j. vetimm.2006.03.007

Yang Z et al (2015) Bovine TLR2 and TLR4 mediate Cryptosporidium parvum recognition in bovine intestinal epithelial cells. Microb Pathog 85:29-34. https://doi.org/ 10.1016/j.micpath.2015.05.009

Zhan K, Lin M, Liu MM, Sui YN, Zhao GQ (2017) Establishment of primary bovine intestinal epithelial cell culture and clone method. In Vitro Cell Dev Biol Anim 53:54-57. https://doi.org/10.1007/s11626-016-0082-5

Publisher's Note Springer Nature remains neutral with regard to jurisdictional claims in published maps and institutional affiliations. 